\title{
Heterogeneous versus Homogeneous electron transfer reactions at liquid-liquid interfaces: The wrong question?
}

Pekka Peljo*, Evgeny Smirnov, and Hubert. H. Girault

Laboratoire d'Electrochimie Physique et Analytique, École Polytechnique Fédérale de Lausanne, EPFL Valais Wallis, Rue de l'Industrie 17, Case Postale 440, CH-1951 Sion, Switzerland

*Corresponding Authors:

E-mail: pekka.peljo@epfl.ch,

ABSTRACT: The exact mechanism of the electron transfer reactions at liquid-liquid interfaces still remains a source of interrogation. The purpose of this paper is to revisit this topic using a finite element simulation approach to analyze cyclic voltammograms for some previously published systems. Also, we compare the current obtained in the absence or presence of an adsorbed gold nanoparticle film. The current results indicate that the electron transfer between ferrocene in the organic phase and hexacyanoferrate(III) in the aqueous phase takes place by potential independent homogeneous reaction in the aqueous phase, while the observed potential dependence stems from that of the concomitant ion transfer reaction of ferrocenium. In the presence of the interfacial gold nanofilm the electron transfer takes place by a bipolar mechanism where the electrons are shuttled through the metallic nanofilm.

KEYWORDS: liquid-liquid interfaces, electron transfer, ion transfer, finite element simulations, redox catalysis 


\section{Graphical abstract}

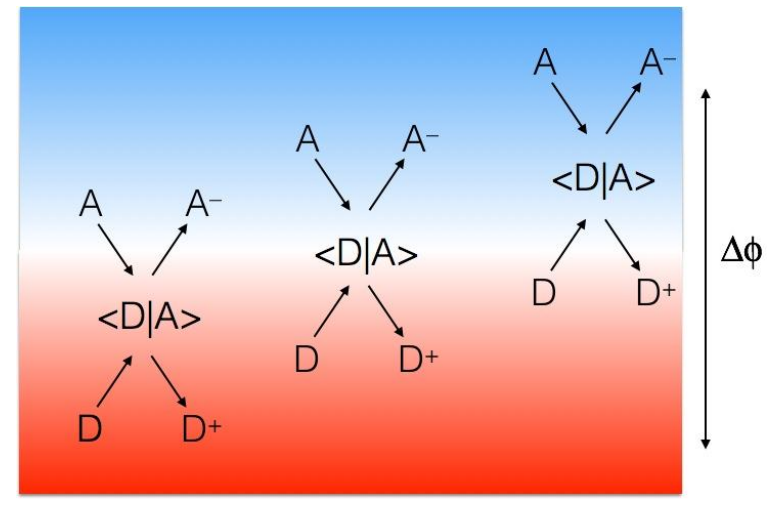

\section{Introduction}

Since the early days of electrochemistry at liquid-liquid interfaces, it was quickly realized that it was possible to polarize the interface between two immiscible electrolytes by building up two face-to-face Gouy-Chapman layers [1,2]. Then, a lot of emphasis was given to ion transfer reactions. These reactions are fast, potential dependent and by now rather well understood $[2,3]$. Following the pioneering work of Koryta et al. [4-6], assisted ion transfer reactions were investigated using an ionophore, mainly in the organic phase to facilitate the transfer of aqueous ions.

Then, attention was given to electron transfer reactions between a donor (D) in one phase and an acceptor (A) in the other phase. Since the early work of Samec et al. [7-9] and others [10], who had shown that a current could be measured when ferrocene was used as an organic donor and ferrocyanide as an aqueous acceptor, heterogeneous electron reactions at polarized liquid-liquid interfaces have remained a source of interrogation. Indeed, the main question is: How much of the total interfacial potential drop does the precursor $<\mathrm{D} \mid \mathrm{A}>$ "feel" at the interface? Where does the potential dependence of the observed current stem from? Do some reactants either D or A partition prior to homogeneous electron transfer reactions, and in this case is the current measured due to ion transfer reactions or either the charged reactant or charged product? This problem is actually somewhat analogous to facilitated ion transfer, that can take place according to at least four different mechanisms, and the differentiation of these mechanisms is very difficult $[2,3]$. 
Heterogeneous electron transfer reactions at ITIES are known to be potential dependent, i.e. dependent of the interfacial polarization but it is difficult to evaluate how much of the overall polarization is active as a local driving force. In early days, these reactions were thought to be truly heterogeneous ET, as suggested by Samec et al. [11,12], for the system comprising $\mathrm{K}_{3 / 4}\left[\mathrm{Fe}(\mathrm{CN})_{6}\right]$ in water and ferrocene in the organic phase meaning that one aqueous redox couple is supposed to react with an organic redox species only at the interface where electron transfer reactions occur. Then, it had been postulated e.g. by Kihara et al. [13], Osakai et al. [14] and Katano et al. $[15,16]$ that one of the reactant can in fact partition to undergo an homogenous ET with associated ion transfer reactions and that the current measured was not always due to an heterogeneous ET but rather to the preceding or following ion transfer reaction.

Using simple techniques such has cyclic voltammetry did not really help in resolving the matter. Of course, a methodology to treat heterogeneous electron transfer reactions were developed for example by Stewart et al. [17], and by Senda et al. for normal pulse voltammetry [18]. New techniques based on scanning electrochemical microscopy were then used and for example, Mirkin et al. concluded, "The observed change in the ET rate with the interfacial potential drop cannot be attributed to concentration effects and represents the potential dependence of the apparent rate constant" [19]. However, they later concluded that "the rate constant of ET across the ITIES is essentially independent of interfacial potential drop when the organic redox reactant is a neutral species" [20]. Similarly, Shi and Anson also reported potential independent ET utilizing thin layer cell voltammetry [21], although Unwin et al. later showed that this observation may have been due to the diffusion limitations [22].

Recently, Aoki et al. have reported, by re-examining the work of Shi and Anson [21], that the electron transfer reaction may actually take place via a self-emulsification of aqueous droplets containing the hydrophobic redox couple in to the organic phase. The self-emulsification occurs due to the mixing entropy even without surfactants [23]. This has been verified experimentally by observing oil droplets in aqueous phase by both voltammetry and dynamic light scattering [24], and observation of water droplets near the liquid-liquid interface by optical microscopy [25].

These conflicting results on the potential dependence of the electron transfer arise from the poor understanding of the potential distribution within the interfacial layers. The question remains, 
which mechanism operates in the electron-transfer process at liquid/liquid interfaces? Recently, Li Niu et al. [26] argued (based on the earlier work by Schmickler [27]) that the potential drop at the interface is mostly at the organic phase, and hence change of the Galvani potential difference only changes the surface concentrations, leading to a change in the reaction rate. Samec argued that this assumption is unjustified, as the potential drop is located at the nanoscopic interface [28]. Girault et al. estimated that $c a$. $30 \%$ of the potential drop is within the inner layer, so that the electron transfer kinetics depend on the Galvani potential difference and the diffuse layer effects (Frumkin effect) [29]. More recently, X-ray reflectivity and molecular dynamics simulations have indicated that the potential drop is very sharp: the electron density profile shows a sharp change over $0.2 \mathrm{~nm}$ distance [30], and electric potential difference simulated for a slab of water-DCE-water shows a similar sharp decrease [31]. So far, X-ray reflectivity and molecular dynamics have not been applied to study electron transfer reactions, but these techniques would help to elucidate how the reactions actually happen. Recently, molecular dynamics simulations have been employed to study photoinduced electron transfer between coumarin 314 and $N, N$-dimethylaniline [32].

Spectroscopic techniques such as surface second harmonic generation [33], potential modulated fluorescence [29] etc. have also been utilized to study interfacial electron transfer reactions, as well as time-resolved Raman [34]. From all these studies, it is clear that the difficulty in defining molecularly interfaces makes it difficult in truly defining heterogeneous electron transfer reactions.

The purpose of this paper is to revisit this topic using a finite element simulation approach to analyze cyclic voltammograms for some previously published systems. Also, we compare the current obtained in the absence or presence of an adsorbed gold nanoparticle film, because addition of gold nanofilm changes the reaction mechanism to purely heterogeneous interfacial electron transfer, where the electrons are shuttled through the gold nanoparticles, allowing more accurate determination of formal potentials of the organic redox couple.

\section{Material and methods}




\subsection{Chemicals}

All chemicals were used as received without further purification. All aqueous solutions were prepared with ultrapure water (MilliporeMilli-Q, specific resistivity $18.2 \mathrm{M} \Omega \cdot \mathrm{cm}$ ). Bis(triphenylphosphoranylidene)ammonium chloride (BACl 98\%), tetramethylammonium chloride (TMACl 98\%), tetrapropylammonium chloride (TPropACl 98\%), lithium chloride (LiCl $>99 \%$ ), lithium sulfate $\left(\mathrm{Li}_{2} \mathrm{SO}_{4}>99 \%\right)$, Dichlorodimethylsilane (DCDMS) and Ferrocene (Fc) were purchased from Fluka. $\alpha, \alpha, \alpha$-trifluorotoluene (TFT 99\% +) was purchased from Acros. Bis(triphyenlylphosphoranylidene) ammonium tetrakis-(pentafluorophenyl)borate (BATB) was prepared by metathesis of aqueous equimolar solutions of $\mathrm{BACl}$ and lithium tetrakis(pentafluorophenyl)-borate ethyl etherate (LiTB purum, Boulder Scientific). The resulting precipitates were filtered, washed, and recrystallized from an acetone:methanol (1:1) mixture.

$38 \mathrm{~nm}$ diameter gold nanoparticles (AuNPs) were synthesized by seed-mediated growth and used for functionalization of the liquid-liquid interface with a gold nanofilm as reported earlier [35]. Detailed characterization of the particles and the nanofilm has been reported in ref. [35].

\subsection{Electrochemical measurements}

All ITIES voltammetry measurements at the water-TFT interface were performed using a fourelectrode cell following the configuration described previously by Hatay et al. [36] and illustrated in Scheme 1. CVs of electron transfer between Fc in the organic phase and a mixture of $\left[\mathrm{Fe}(\mathrm{CN})_{6}\right]^{3-/ 4-}$ in the aqueous phase were recorded, with the ratio between $\left[\mathrm{Fe}(\mathrm{CN})_{6}\right]^{3-}$ and $\left[\mathrm{Fe}(\mathrm{CN})_{6}\right]^{4-}$ selected as described in Scheme 1A. Low concentrations of Fc $(0.1$ to $0.5 \mathrm{mM})$ were used in order to avoid the presence of $\mathrm{Fc}^{+}$peak on $\mathrm{CVs}$, which normally exists at ambient conditions with oxygen [37,38]. The set of experiments was carried out with either $100 \mathrm{mM} \mathrm{LiCl}$ (Scheme 1A) or $10 \mathrm{mM} \mathrm{Li}_{2} \mathrm{SO}_{4}$ (Scheme 1B) as supporting electrolyte. Additional experiments were carried out with lower $\left[\mathrm{Fe}(\mathrm{CN})_{6}\right]^{3-/ 4-}$ concentrations, at different scan rates. 
(A)

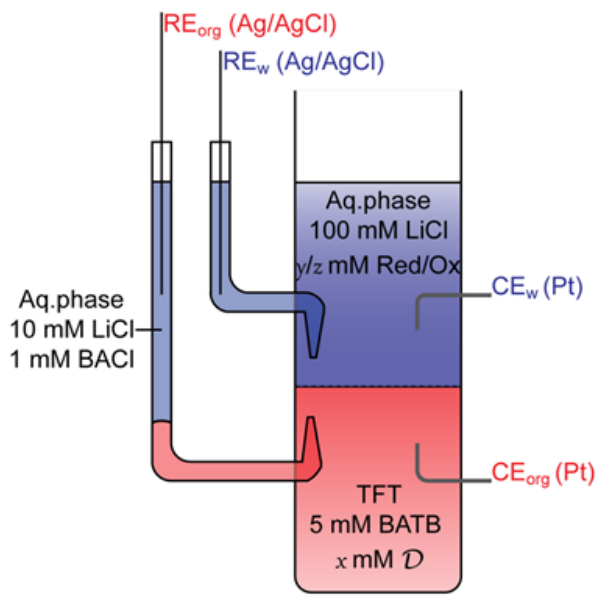

(B)

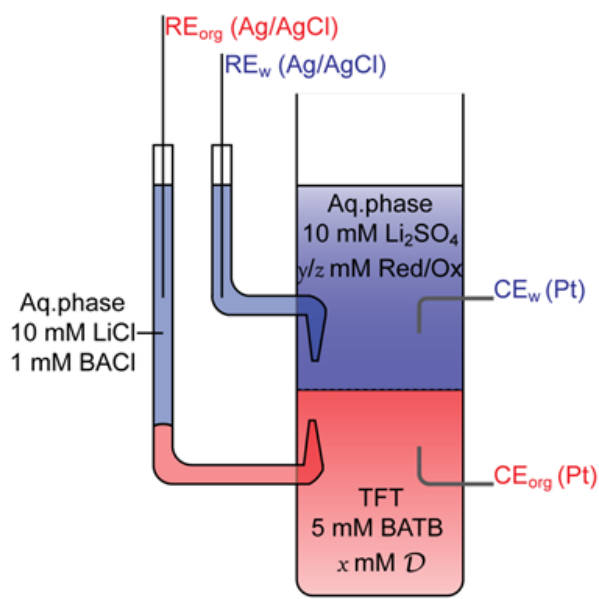

\begin{tabular}{cccc}
\hline & $\begin{array}{c}x \mathrm{mM} \\
\mathcal{D}(\mathrm{Fc})\end{array}$ & $\begin{array}{c}y \mathrm{mM} \\
\mathrm{K}_{\mathbf{4}} \mathrm{Fe}(\mathrm{CN})_{\mathbf{6}}\end{array}$ & $\begin{array}{c}z \mathrm{mM} \\
\mathrm{K}_{\mathbf{3}} \mathrm{Fe}(\mathrm{CN})_{6}\end{array}$ \\
\hline Cell 1 & 0.1 & 10 & 100 \\
Cell 2 & 0.1 & 55 & 55 \\
Cell 3 & 0.1 & 100 & 10 \\
\hline
\end{tabular}

\begin{tabular}{lccc}
\hline & $\begin{array}{c}x \mathrm{mM} \\
\mathcal{D}(\mathrm{Fc})\end{array}$ & $\begin{array}{c}y \mathbf{~ m M} \\
\mathrm{K}_{\mathbf{4}} \mathrm{Fe}(\mathrm{CN})_{6}\end{array}$ & $\begin{array}{c}z \mathrm{mM} \\
\mathrm{K}_{3} \mathrm{Fe}(\mathrm{CN})_{6}\end{array}$ \\
\hline Cell 4 & 0.1 & 10 & 100 \\
Cell 5 & 0.1 & 1 & 10 \\
Cell 6 & 0.1 & 0.1 & 1 \\
Cell 7 & 0.5 & 10 & 100 \\
\hline
\end{tabular}

Scheme 1. Composition of four electrode cells: (A) with $100 \mathrm{mM} \mathrm{LiCl}$ and (B) $10 \mathrm{mM} \mathrm{Li}_{2} \mathrm{SO}_{4}$ as supporting electrolyte. $\mathcal{D}$ denotes electron-donor molecules such as Fc.

Two platinum electrodes provide current whereas two $\mathrm{Ag} / \mathrm{AgCl}$ reference electrodes allow measurement and correction of the polarization across the interface with PGSTAT 30 and PGSTAT 101 (Metrohm, Switzerland) potentiostats. Ag/AgCl reference electrode gave a stable potential also in Cells 4-7. The Galvani potential difference, in accordance with the TATB assumption [39], was calibrated by addition of internal standards $\mathrm{TMA}^{+}$and $\mathrm{TProA}^{+}$ions, whose $\Delta_{\mathrm{o}}^{\mathrm{w}} \phi_{1 / 2}$ at the water-TFT interfaces were taken to be $+0.270 \mathrm{~V}$ and $-0.019 \mathrm{~V}$ for $\mathrm{TMA}^{+}$and TProA $^{+}$, respectively [40-42]. 


\section{Theory}

Generally the electron transfer reaction between electron donor D in the organic phase and an electron acceptor $\mathrm{A}$ in the aqueous phase proceeds by formation of a $\langle\mathrm{D} \mid \mathrm{A}\rangle$ intermediate at the transition state. To consider the questions posed in the introduction, namely: i) How much of the total interfacial potential drop does the precursor $\langle\mathrm{D}| \mathrm{A}>$ "feel" at the interface? ii) Where does the potential dependence of the observed current stem?, finite element simulations of different possible scenarios were performed. The possible pathways are

$$
\begin{aligned}
& \mathrm{D}(\mathrm{o})+\mathrm{A}(\mathrm{w}) \underset{k_{\mathrm{b} 1}}{\stackrel{k_{\mathrm{f} 1}}{\rightleftarrows}}<\mathrm{D} \mid \mathrm{A}>(\mathrm{o}) \underset{k_{\mathrm{b} 2}}{\stackrel{k_{\mathrm{f} 2}}{\rightleftarrows}} \mathrm{D}^{+}(\mathrm{o})+\mathrm{A}(\mathrm{w}) \\
& \mathrm{D}(\mathrm{o})+\mathrm{A}(\mathrm{w}) \underset{k_{\mathrm{b} 1}}{\stackrel{k_{\mathrm{f} 1}}{\rightleftarrows}}<\mathrm{D} \mid \mathrm{A}>(\text { interface }) \underset{k_{\mathrm{b} 2}}{\stackrel{k_{\mathrm{f} 2}}{\rightleftarrows}} \mathrm{D}^{+}(\mathrm{o})+\mathrm{A}(\mathrm{w}) \\
& \mathrm{D}(\mathrm{o})+\mathrm{A}(\mathrm{w}) \underset{k_{\mathrm{b} 1}}{\stackrel{k_{\mathrm{f} 1}}{\rightleftarrows}}<\mathrm{D} \mid \mathrm{A}>(\mathrm{w}) \underset{k_{\mathrm{b} 2}}{\stackrel{k_{\mathrm{f} 2}}{\rightleftarrows}} \mathrm{D}^{+}(\mathrm{o})+\mathrm{A}(\mathrm{w})
\end{aligned}
$$

Obviously, reactions (1) and (3) (organic or aqueous pre-partitioning mechanisms, respectively) require one of the reactants to partition into the other phase before the reaction. As the transfer of $\left[\mathrm{Fe}(\mathrm{CN})_{6}\right]^{3}$ and $\left[\mathrm{Fe}(\mathrm{CN})_{6}\right]^{4}$ into the organic phase requires very negative potentials, reaction (3) is unlikely. Unfortunately, the simulations of the electric double layer effects are very challenging to implement accurately, so the potential drop was assumed to occur fully at the liquid-liquid interface. The effect of the electric double layer was only considered indirectly by varying the charge transfer coefficient for the interfacial electron transfer in reaction (2) (heterogeneous electron transfer mechanism). Samec has argued that low values of $\alpha$ can be reasonable due to the strong repulsion of negatively charged ferricyanide from the electric double layer on the aqueous side, due to the Frumkin effect $[8,28]$.

Additionally, Aoki et al. have recently demonstrated that the electron transfer reaction at liquidliquid interfaces can be influenced by self-emulsification of the both phases, leading to formation of small droplets of water in the organic phase and small droplets of oil in the aqueous phase. As some $\mathrm{Fc}$ will remain in the oil droplets and $\left[\mathrm{Fe}(\mathrm{CN})_{6}\right]^{3}$ in the water droplets, the ET reaction may proceed also "homogenously" within both oil and aqueous phase due to this self- 
emulsification [43]. However, this mechanism is difficult to implement in the simulations accurately, so it was not considered in this work.

The model equations used to simulate these voltammograms with COMSOL Multiphysics v.5.2 are described in the Supplementary material, sections S1 and S2. Following reactions take place at the liquid-liquid interface:

$$
\begin{aligned}
& \mathrm{Fc}(\mathrm{o})+\left[\mathrm{Fe}(\mathrm{CN})_{6}\right]^{3}(\mathrm{w}) \underset{k_{\mathrm{ET}, \mathrm{b}}}{\stackrel{k_{\mathrm{ET}, \mathrm{f}}}{\rightleftarrows}} \mathrm{Fc}^{+}(\mathrm{o})+\left[\mathrm{Fe}(\mathrm{CN})_{6}\right]^{4}(\mathrm{w}) \quad \text { (heterogeneous ET) } \\
& \mathrm{Fc}(\mathrm{w}) \underset{k_{\mathrm{p}, \mathrm{b}}}{\stackrel{k_{\mathrm{p}, \mathrm{f}}}{\rightleftarrows}} \mathrm{Fc}(\mathrm{o}) \quad \text { (partition of ferrocene) } \\
& \mathrm{Fc}^{+}(\mathrm{W}) \underset{k_{\mathrm{TT}, \mathrm{b}}}{\stackrel{k_{\mathrm{TT}, \mathrm{f}}}{\rightleftarrows}} \mathrm{Fc}^{+}(\mathrm{o}) \quad \text { (IT of ferrocenium) } \\
& \mathrm{K}^{+}(\mathrm{W}) \underset{k_{\mathrm{IT} 2, \mathrm{~b}}}{\stackrel{k_{\mathrm{TT}, \mathrm{f}}}{\rightleftarrows}} \mathrm{K}^{+}(\mathrm{o}) \quad \text { (IT of } \mathrm{K}^{+} \text {cation) }
\end{aligned}
$$

where $\mathrm{K}^{+}$is the metal cation from the ferro-ferricyanide salts. The kinetics of these reactions were assumed to follow a Butler-Volmer formalism, as described in the Supplementary material. As Fc can partition into the aqueous phase according to Eq. (5), it will react homogeneously with $\mathrm{Fe}(\mathrm{III})$ :

$$
\mathrm{Fc}(\mathrm{w})+\left[\mathrm{Fe}(\mathrm{CN})_{6}\right]^{3}(\mathrm{w}) \underset{k_{1}}{\stackrel{k_{1}}{\rightleftarrows}} \mathrm{Fc}^{+}(\mathrm{w})+\left[\mathrm{Fe}(\mathrm{CN})_{6}\right]^{4}(\mathrm{w})
$$

The equilibrium constant $K_{\mathrm{hom}}=k_{1} / k_{-1}$ can be evaluated when the redox potentials of both redox couples are known. $\left[E_{\mathrm{Fc}^{+} / \mathrm{Fc}}^{0^{\prime}}\right]_{\mathrm{W}}=0.381 \mathrm{~V}$ vs. SHE [44] and the formal potential for ferroferricyanide $\left[E_{\mathrm{Fe}(\mathrm{CN})_{6}^{3} / \mathrm{Fe}(\mathrm{CN})_{6}^{4}}^{0^{\prime}}\right]_{\mathrm{W}}$ was evaluated as $0.467 \mathrm{~V}$ vs. SHE in $100 \mathrm{mM} \mathrm{LiCl} \mathrm{[35]} \mathrm{and} \mathrm{as}$ $0.4445 \mathrm{~V} v s$. SHE in $10 \mathrm{mM} \mathrm{Li}_{2} \mathrm{SO}_{4}$ in this work. The equilibrium constant for the reaction (8) can be calculated as

$$
K_{\mathrm{hom}}=\exp \left(\frac{G}{R T}\right)=\exp \left(\frac{F}{R T}\left(\left[E_{\mathrm{Fe}(\mathrm{CN})_{6}^{3} / \mathrm{Fe}(\mathrm{CN})_{6}^{4}}^{0^{\prime}}\right]_{\mathrm{w}}\left[E_{\mathrm{Fc}^{+} / \mathrm{Fc}}^{0^{\prime}}\right]_{\mathrm{w}}\right)\right)=30.1(\mathrm{LiCl})
$$

or $12.4\left(\mathrm{Li}_{2} \mathrm{SO}_{4}\right)$ 
The kinetics for partition of neutral ferrocene were employed by calculating the partition coefficient of $\mathrm{Fc}, K_{\mathrm{p}}$, setting $k_{\mathrm{P}, \mathrm{b}}$ as $0.1 \mathrm{~cm} \mathrm{~s}^{-1}$ and calculating the forward rate constant $k_{\mathrm{P}, \mathrm{f}}=K_{p} k_{\mathrm{P}, \mathrm{b}}$. Partition coefficient of Fc between TFT and water was calculated from the thermodynamic cycle as described by Fermin and Lahtinen [45]. Briefly, standard potential of a redox couple in organic solvent can be expressed with the help as the redox potential in water and the Gibbs energies of transfer of reduced and oxidized species from water to oil:

$\left[E_{\mathrm{ox} / \mathrm{red}}^{0^{\prime}}\right]_{\mathrm{o}}=\left[E_{\mathrm{ox} / \mathrm{red}}^{0^{\prime}}\right]_{\mathrm{w}}+\frac{G_{\mathrm{ox}}^{0, \mathrm{w} \rightarrow \mathrm{o}} G_{\mathrm{red}}^{0, \mathrm{w} \rightarrow 0}}{F}$

Hence, the formal potential of Fc in TFT can be expressed as

$$
\left[E_{\mathrm{Fc}^{+} / F c}^{0^{\prime}}\right]_{0}=\left[E_{\mathrm{Fc}^{+} / \mathrm{Fc}}^{0^{\prime}}\right]_{\mathrm{w}}+\begin{array}{ccc}
\mathrm{w} & 0^{\prime} \\
0 & \mathrm{Fc}^{+} & \frac{G_{\mathrm{Fc}}^{0, \mathrm{w} \rightarrow 0}}{F}
\end{array}
$$

This equation can be used to calculate the transfer energy and also partition coefficient of $\mathrm{Fc}$ from water to TFT (standard redox potentials of $\mathrm{Fc}$ in water $\left(\left[E_{\mathrm{Fc}^{+} / \mathrm{Fc}}^{0^{\prime}}\right]_{\mathrm{w}}=0.381 \mathrm{~V} v s\right.$. SHE [44]) and TFT $\left(\left[E_{\mathrm{Fc}^{+} / \mathrm{Fc}}^{0^{\prime}}\right]_{\mathrm{o}}=0.736 \mathrm{~V}\right.$ vs. SHE as obtained in this work, vide infra, or $0.720 \mathrm{~V}$ vs. SHE [35]) are known, and $\begin{array}{lll}\mathrm{w} & 0^{\prime} \\ \mathrm{o} & \mathrm{Fc}^{+}\end{array}$was taken as the half-wave potential of $\Delta_{\mathrm{o}}^{\mathrm{w}} \phi_{1 / 2, \mathrm{Fc}^{+}}=0.115 \mathrm{~V}$ [35]) as $K_{p, \mathrm{Fc}}=\exp \left(-\frac{\Delta G_{\mathrm{Fc}}^{0, \mathrm{w} \rightarrow \mathrm{o}}}{R T}\right)=13373$

This partition coefficient is similar to the values measured between water and DCE [45] and water and nitrobenzene [14].

When a gold nanofilm [35] was added at the interface, the system was considered as a metallic electrode in between the two phases, where the reactions are only oxidation of $\mathrm{Fc}$ at the oil side and reduction of Fe(III) in the aqueous phase, similarly to bipolar cells [46].

$\mathrm{Fc}(\mathrm{o}) \underset{k_{\text {o,red }}}{\stackrel{k_{0,0 x}}{\rightleftarrows}} \mathrm{Fc}^{+}(\mathrm{o})+e^{-}$ 


$$
\left[\mathrm{Fe}(\mathrm{CN})_{6}\right]^{4}(\mathrm{w}) \underset{k_{\mathrm{w}, \text { red }}}{\stackrel{k_{\mathrm{w}, 0 x}}{\rightleftarrows}}\left[\mathrm{Fe}(\mathrm{CN})_{6}\right]^{3}(\mathrm{w})+e
$$

In this case, simulations were performed in conditions where aqueous redox couple was always in hundred-fold excess. Hence, the Fermi level of the AuNPs was fixed by the ferro-ferricyanide redox couple $\left(E_{\mathrm{NP}} \approx\left[E_{\mathrm{FeCN}_{6}^{3} / \mathrm{FeCN}_{6}^{4}}^{0^{\prime}}\right]_{\mathrm{w}}+{ }_{\mathrm{w}}\right)$, and the overpotential is mostly on the oil side [35]. For example, the overpotential with the $\mathrm{Fe}(\mathrm{II}) / \mathrm{Fe}(\mathrm{III})$ ratio of $1 / 10$ in the aqueous phase was only $0.4 \mathrm{mV}$ at the positive potential limit of the scan.

\section{Results and Discussion}

\subsection{Electron transfer across the liquid-liquid interface}

\subsubsection{Homogeneous and heterogeneous mechanisms}

As discussed above, the electron transfer reaction between Fc in the TFT phase and Fe(III) in the aqueous phase can proceed in two ways: i) interfacial bimolecular electron transfer (ET) or ii) partition of neutral Fc into the aqueous phase, followed by homogeneous electron transfer and subsequent ion transfer of $\mathrm{Fc}^{+}$back from aqueous to organic phase. In the first case, the current observed experimentally arises from the flux of electrons across the ITIES (bimolecular ET mechanism), while in the latter case the observed current comes from the transfer of $\mathrm{Fc}^{+}$ions from water to oil (homogeneous ET-IT mechanism).

Simulations were performed to evaluate which mechanism operates at the interfacial electron transfer reaction at water-TFT interfaces. For the case without a gold film, an heterogeneous bimolecular electron transfer between $\mathrm{Fc}$ in TFT and $\left[\mathrm{Fe}(\mathrm{CN})_{6}\right]^{3-}$ following the Butler-Volmer kinetics was included in the model, with the ion transfer mechanism proposed by Osakai et al. [14], where Fc first partitions into the aqueous phase to react homogeneously with $\mathrm{Fe}^{3+}$ and is transferred back across the ITIES as $\mathrm{Fc}^{+}$. As calculated in Eq. 12, the partition coefficient of Fc between TFT and water was estimated to be $c a$. 13400. Both the bimolecular rate constant for the ET reaction and the homogeneous ET rate constants were varied in order to reproduce 
experimental results from the cyclic voltammetry. Two scans were simulated for comparison of the $2^{\text {nd }}$ experimental scan. Simulations of bimolecular ET mechanism alone in Fig. $1 \mathrm{a}$ and $\mathrm{b}$ clearly show that this mechanism cannot satisfactory reproduce experimental CVs. However, the simulations done considering only the partition of ferrocene (Fig. 1c) followed by homogeneous electron transfer and transfer of $\mathrm{Fc}^{+}$ions across the interface show good agreement with the experimental data. In this case, the homogeneous rate constant was found to have a significant influence on the shape and peak current magnitude of the simulated CVs. Figure 1c shows that increasing homogeneous rate constant increases the observed reversibility of the signal. Unfortunately, the simulated data obtained with $k_{1}=1 \times 10^{9} \mathrm{~s}^{-1} \mathrm{M}^{-1}$ does not provide a satisfactory match between all sets of the experimental data for different $\mathrm{Fe}(\mathrm{CN})_{6}^{3-14}$ concentrations (Fig. 1d). This point will be discussed vide infra.
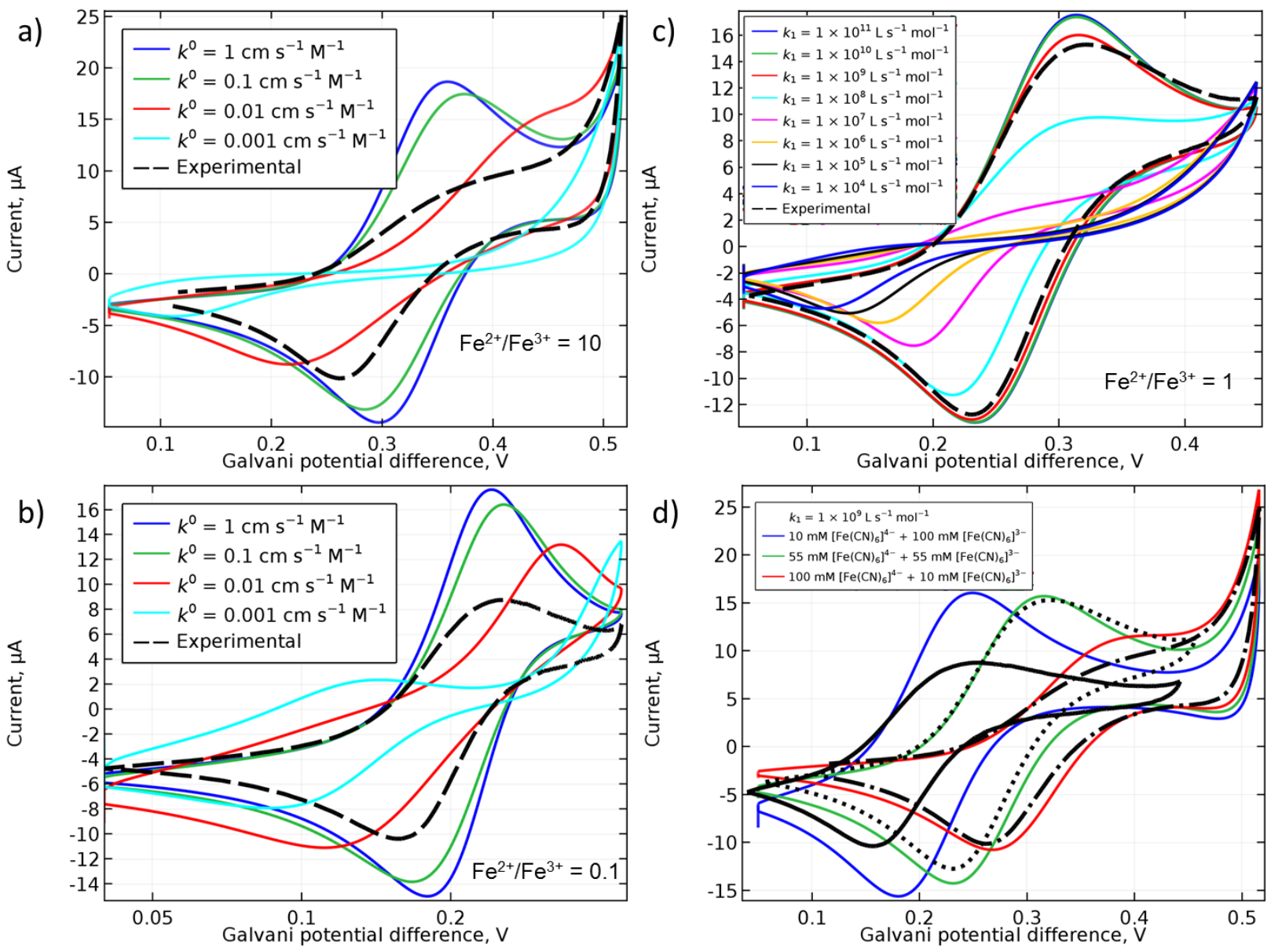

Figure 1. Effect of the standard rate constant on the simulated cyclic voltammograms considering only heterogeneous electron transfer. Experimental and simulated CVs for cell 
compositions 1 (a) and 3 (b) in Scheme $1\left(\mathrm{Fe}^{2+/ 3+}\right.$ ratios of 10 to 100 and 100 to 10 respectively) are presented. c) Effect of the homogeneous rate constant on the simulated cyclic voltammograms considering only homogeneous electron transfer in the aqueous phase, for cell composition 2 in Scheme $1\left(\mathrm{Fe}^{2+/ 3+}\right.$ ratio of 55 to 55). d) Simulated cyclic voltammograms considering only partition of ferrocene followed by homogeneous electron transfer and transfer of $\mathrm{Fc}^{+}$ions across the interface, with three different concentration ratios of $\mathrm{Fe}^{2+/ 3+}$ in the aqueous phase. Homogenous reaction rate $k_{1}=1 \times 10^{9} \mathrm{~s}^{-1} \cdot \mathrm{M}^{-1}$. Scan rate $10 \mathrm{mV} \cdot \mathrm{s}^{-1}$, only the second scan is shown.

To successfully match the experimental voltammograms, the homogeneous rate constant had to be varied from $2 \times 10^{8} \mathrm{~s}^{-1} \cdot \mathrm{M}^{-1}$ to $1 \times 10^{10} \mathrm{~s}^{-1} \cdot \mathrm{M}^{-1}$ to $5 \times 10^{9} \mathrm{~s}^{-1} \cdot \mathrm{M}^{-1}$ for $\mathrm{Fe}^{2+/ 3+}$ ratios of $10 \mathrm{mM} /$ $100 \mathrm{mM}, 55 \mathrm{mM} / 55 \mathrm{mM}$, and $100 \mathrm{mM} / 10 \mathrm{mM}$, in the aqueous phase, respectively (Fig. 2). Additionally, if both mechanisms are included in the model, the contribution from the bimolecular ET mechanism is extremely small. Hence, this approach suggests that the electron transfer takes place almost solely by the partitioning of the ferrocene followed by homogeneous electron transfer in the aqueous phase and finally by the transfer of ferrocenium into the organic phase, as suggested by Osakai et al. [14]. 
(A)

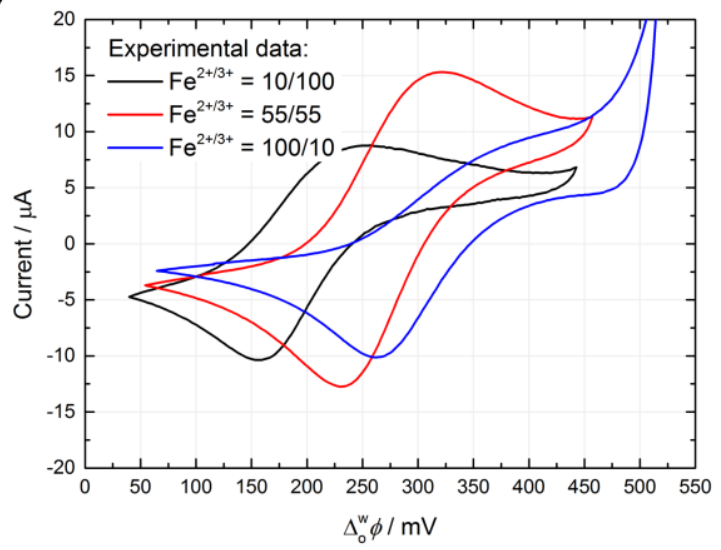

(B)

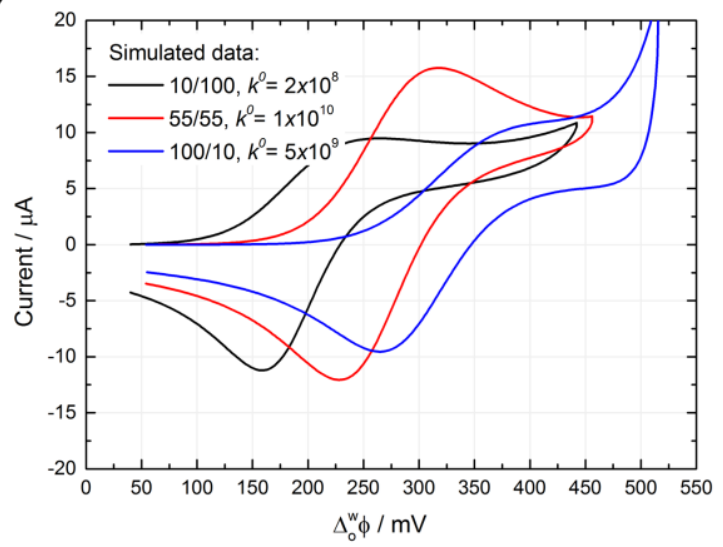

Figure 2. Effect of the homogeneous rate constant for different concentration of $\left[\mathrm{Fe}(\mathrm{CN})_{6}\right]^{3-}$ 14- (A) Experimental and (B) simulated cyclic voltammograms (IR compensated) of $0.1 \mathrm{mM} \mathrm{Fc}$ and $5 \mathrm{mM}$ BATB solution in TFT and $\left[\mathrm{Fe}(\mathrm{CN})_{6}\right]^{3-/ 4-}$ with various ratio between $\mathrm{Fe}^{2+}$ and $\mathrm{Fe}^{3+}$ (Cells 1-3 in Scheme 1) at scan rate $10 \mathrm{mV} / \mathrm{s}$. The homogeneous rate constant was varied from 2 $\times 10^{8} \mathrm{~s}^{-1} \cdot \mathrm{M}^{-1}$ to $1 \times 10^{10} \mathrm{~s}^{-1} \cdot \mathrm{M}^{-1}$ to $5 \times 10^{9} \mathrm{~s}^{-1} \cdot \mathrm{M}^{-1}$.

The exact reproduction of experimental voltammograms is far from simple, as many of the parameters are not accurately known. It has been shown that iron hexacyano-complexes form ion pairs with cations $[47,48]$, inhibiting the ion transfer of potassium at the positive end of the potential window. This effect as well as the effects of activities was disregarded in the model, and the standard transfer potential of potassium was tuned to $0.75 \mathrm{~V}$ to match the experimental onset of the potassium transfer in all the three different ratios of $\mathrm{Fe}^{2+} / \mathrm{Fe}^{3+}$ resulting in different potassium concentrations. Another difficulty is that the ferrocenium will slowly decompose in the presence of water and oxygen [49-51]. Additionally, after some experiments a blue-green 
precipitate was found to form at the liquid-liquid interface, as reported earlier [52,53]. All these factors contribute to the differences between experimental and simulated voltammograms.

To further investigate this system, $100 \mathrm{mM} \mathrm{LiCl}$ was replaced with $10 \mathrm{mM} \mathrm{Li}_{2} \mathrm{SO}_{4}$ as a supporting electrolyte in Cells 4-7 to minimize the complexation of iron with chloride, and different ratios of $\mathrm{Fc}$ to $\mathrm{Fe}^{3+}$ were tested at different scan rates, with the simulated and experimental CVs shown in Figure 3.
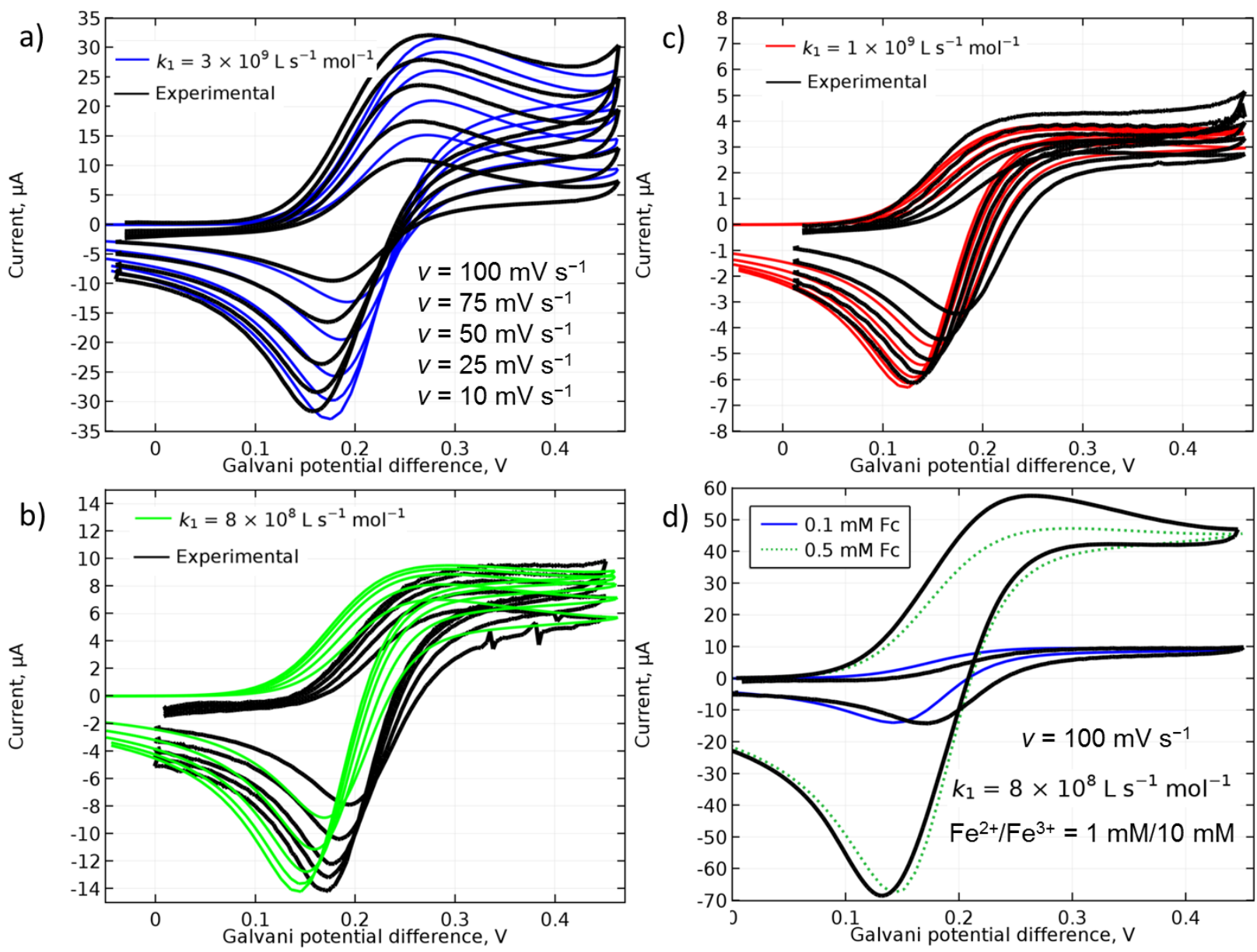

Figure 3. a-c) Experimental and simulated CVs obtained with Cells 4-6 in Scheme 1.- (10/100 $\mathrm{mM} 1 / 10 \mathrm{mM}$ and $0.1 / 1 \mathrm{mM} \mathrm{Fe}^{2+} / \mathrm{Fe}^{3+}$ ). The simulated homogenous rate constants are $3 \times 10^{9} \mathrm{~s}^{-}$ ${ }^{1} \cdot \mathrm{M}^{-1}$ to $8 \times 10^{8} \mathrm{~s}^{-1} \cdot \mathrm{M}^{-1}$ to $1 \times 10^{9} \mathrm{~s}^{-1} \cdot \mathrm{M}^{-1}$. d) Simulated and experimental voltammograms obtained with Cells 5 and 7 in Scheme $1\left(10 / 100 \mathrm{mM} \mathrm{Fe}{ }^{2+} / \mathrm{Fe}^{3+}\right.$ and 0.1 or $\left.0.5 \mathrm{mM} \mathrm{Fc}\right)$.

The slight shifts between some of the experimental results and simulations may be due to the drifting of the $\mathrm{Ag} / \mathrm{AgCl}$ reference electrode in the sulfate media during the experiments, in spite 
of the calibration of the Galvani potential scale with an internal standard after the ET measurements. The voltammogram obtained with the scan rate of $10 \mathrm{mV} \cdot \mathrm{s}^{-1}$ does not match the simulated CV. This may be due to the change in the reaction mechanism: Aoki et al. reported that at scan rates higher than $c a .20 \mathrm{mV} \cdot \mathrm{s}^{-1}$ the electron transfer reaction at thin film modified electrodes was taking place by penetration of the aqueous redox species into the organic film via self-emulsification, while at lower scan rates the ET reaction seemed to be interfacial [43].

The formal potential of all these cases was also measured, with the $10 / 100 \mathrm{mM} \mathrm{Fe} \mathrm{Fe}^{2+} / \mathrm{Fe}^{3+}$ voltammogram showing the typical reversible electron transfer on glassy carbon electrode. However, with lower concentrations of $\mathrm{Fe}^{3+}$, the electron transfer at glassy carbon electrode became very kinetically limited, with very wide peak-to-peak separations, as shown in the Supplementary Material, Figure S-1. This observation further justifies the strong variations of the electron transfer rate constants obtained by simulations. The homogeneous rate constants ranging from $2 \times 10^{7} \mathrm{~s}^{-1} \cdot \mathrm{M}^{-1}$ (digital simulations of cyclic voltammetry [14]) to $9 \times 10^{7} \mathrm{~s}^{-1} \cdot \mathrm{M}^{-1}$ (extrapolation of the measurements performed with micelles [54]) to $3 \times 10^{10} \mathrm{~s}^{-1} \cdot \mathrm{M}^{-1}$ (obtained from normal pulse voltammetry [16]) have been reported in the literature. This large variation reported in the literature and even within our own results reflects the complications with the ferri/ferrocyanide redox couple, which, as it has been shown previously, shows strong ion pairing with different cations $[47,48]$.

Additionally, the self-exchange electron transfer rate with ferri/ferrocyanide has been shown to be significantly catalyzed by the presence of various cations [55]. Also, the formal potential of the redox couple depends strongly on the supporting electrolyte and on the ionic strength. In the present experiments, the ionic strength varied from 1 to $0.04 \mathrm{M}$. Indeed, if the logarithm of the obtained rate constant is plotted considering the long-range Debye-Hückel interactions as the function of $\sqrt{I} /(1+\sqrt{I})$, where $I$ is the ionic strength, a linear correlation is obtained, as shown in Figure 4. 


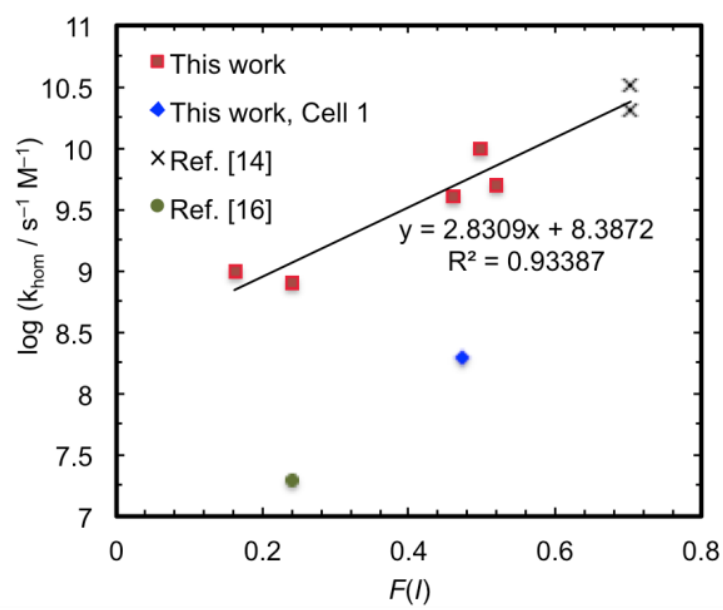

Figure 4. Correlation between logarithm of the rate constant and function $F(I)$ considering the long-range Debye-Hückel interactions. $F(I)=\sqrt{I} /(1+\sqrt{I})$. Points on the graph depict both data obtained in the current study and previously published values (refs. [14] and [16]).

The rate constants determined by Tatsumi and Katano $[15,16]$ also fall on this line, while it seems that there is a outlier measurement at $10 \mathrm{mM} / 100 \mathrm{mM} \mathrm{Fe}^{2+} / \mathrm{Fe}^{3+}$ ratio with $100 \mathrm{mM} \mathrm{LiCl}$ as a supporting electrolyte. The value reported by Osakai et al. [14] is also not on this line, and the reason for this discrepancy is currently not known. One possible explanation might lie in the choice of the cation: the data obtained in this work and by Tatsumi and Katano utilized potassium salts, while Osakai et al. used sodium ferro/ferricyanide. Indeed, the rate of reaction between for example persulfate and ferrocyanide depends strongly on both the type of the cation and the ionic strength [56].

As the rate constants for the homogeneous reaction are very high, the reaction layer thickness is extremely thin, varying from 10 to $100 \mathrm{~nm}$ depending on the initial concentrations and scan rate, as shown in Figure S-2 in the Supplementary material. As the interface between two liquids is molecularly sharp but fluctuating within $c a .1 \mathrm{~nm}$ thickness, (as predicted by molecular dynamics simulations [31] and measured by neutron reflectivity [57]), the reaction layer is only slightly thicker than the interface itself. Furthermore, double layer effects should be considerable at these thicknesses. 
The simulated CVs considering only heterogeneous ET had a different shape and too high magnitude in comparison with the experimental results. However, if the charge transfer coefficient $\alpha$ was adjusted close to 0 , the experimental voltammograms could be reproduced. Osakai et al. reached the same conclusion (they wrote the rate constants slightly differently, so they needed to adjust $\alpha$ close to unity) [14]. The Marcus theory of the ET across the ITIES, predicts that $\alpha$ should be close to 0.5 [58] and thus does not support these low values. Nevertheless, Samec has argued that this could be due to the strong repulsion of negatively charged ferricyanide from the electric double layer, due to the Frumkin effect [28]. Shao et al. reported similar abnormally large transfer coefficients for the ET reactions at water/NPOE interface measured by SECM, and attributed to the Frumkin effect on both sides of the interface [59].

However, Osakai et al. could not fit all their experimental results with the same parameters, so they concluded that "the interfacial ET mechanism could not give a good explanation for the present system" [14]. Our results are very similar to the results of Osakai et al. [14]. The effect of $\alpha$ is shown in Figure 5. The differences between simulated and experimental values are more pronounced when the amount of total iron in the aqueous phase is decreased to $1.1 \mathrm{mM}(0.1 \mathrm{mM}$ $\left.\left[\mathrm{Fe}(\mathrm{CN})_{6}\right]^{4-}+1 \mathrm{mM}\left[\mathrm{Fe}(\mathrm{CN})_{6}\right]^{3-}\right)$ while keeping the ratio of $\mathrm{Fe}(\mathrm{II})$ and $\mathrm{Fe}(\mathrm{III})$ constant and the concentration of $\mathrm{Fc}$ in the organic phase at $0.1 \mathrm{mM}$ (Cell 6 in Scheme 1). In this case almost no positive current was obtained at around $0.2 \mathrm{~V}$, while the peak potential on the reverse scan was shifted by $c a .30 \mathrm{mV}$ compared to the experimental results. 
a)

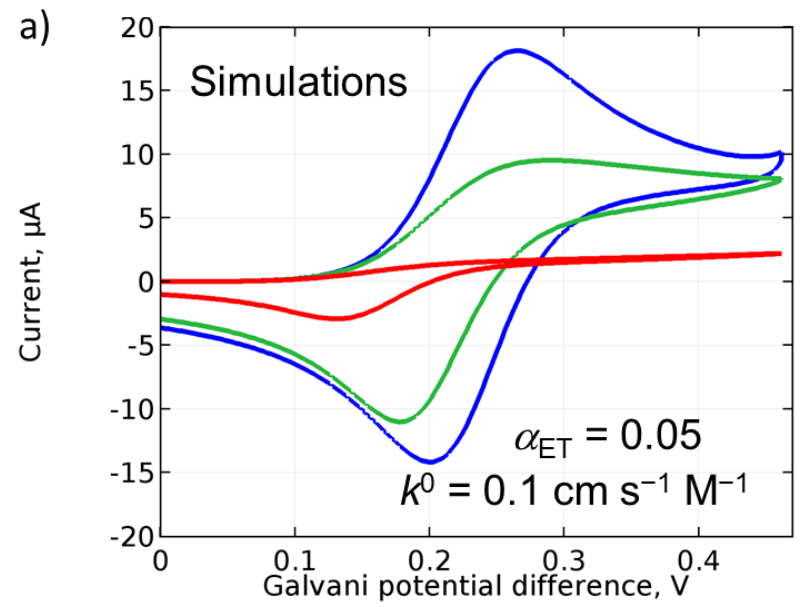

c)

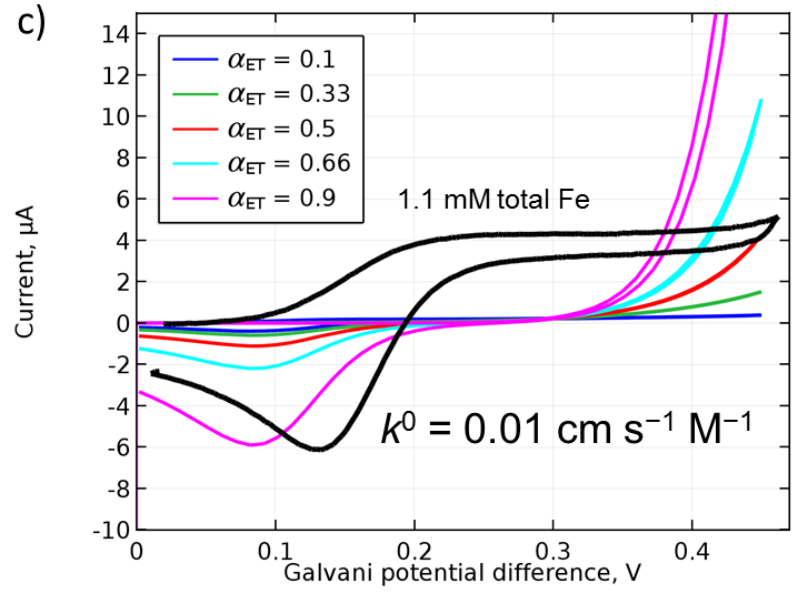

b)

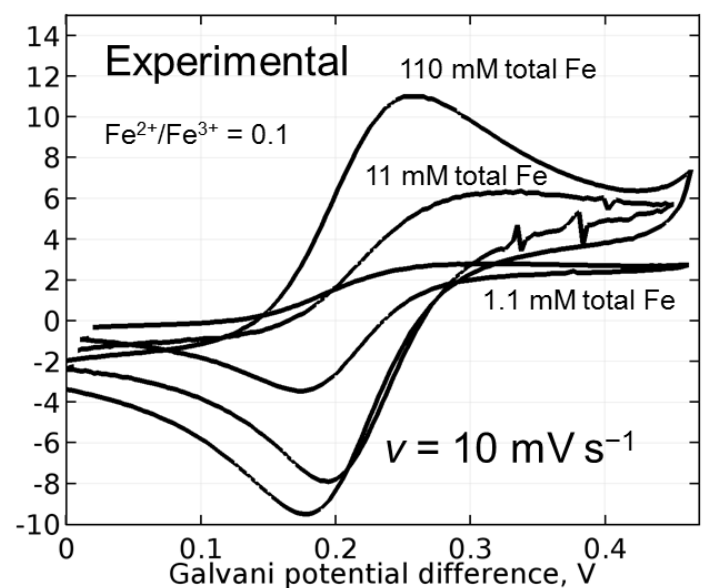

d)

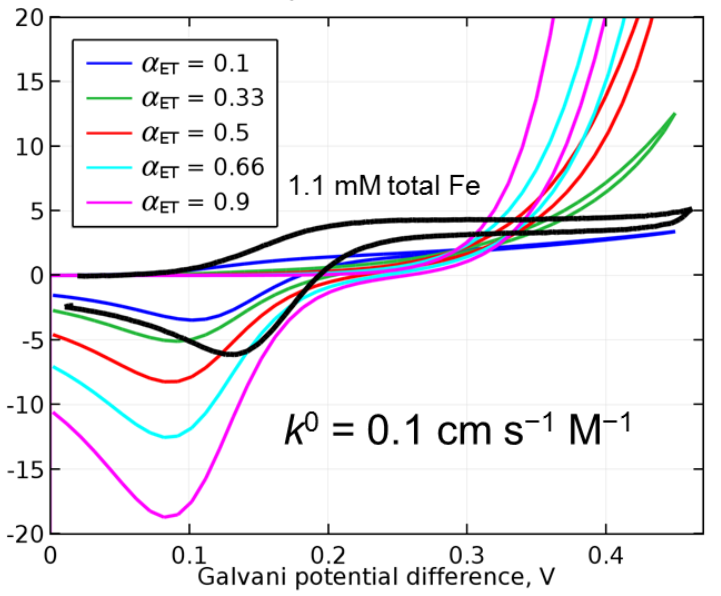

Figure 5. Effect of $\boldsymbol{\alpha}$ on simulated CVs. a-b) The comparison between the experimental CVs and the simulations done with different $\alpha$ value for different amounts of total iron in aqueous phase. c) Comparison of simulations with different $\alpha$ with $0.1 \mathrm{mM} \mathrm{Fe} \mathrm{F}^{2+}$ and $1 \mathrm{mM} \mathrm{Fe} \mathrm{F}^{3+}$ in the aqueous phase for different bimolecular interfacial electron transfer constants (c and d). Scan rate $10 \mathrm{mV} \cdot \mathrm{s}^{-1}$.

However, the experimental data can be reproduced by changing the value of $k^{0}$ for the interfacial reaction, as shown in Figure 6 a). Detailed analysis of the contribution of the different reactions to the total current is shown in Figures 6 b) and c). At low Galvani potential differences the potential independent oxidation of Fc is balanced by the potential dependent reduction reaction, resulting in net zero current. Net current flow is observed only when sufficiently high Galvani potential difference is applied to reduce the rate of the reduction of $\mathrm{Fc}$, allowing the oxidation reaction to proceed. The rate of oxidation reaction then decreases due to decreasing interfacial $\mathrm{Fc}$ concentration. After reversal of the scan direction the rate of the reduction reaction increases, and 
consequently, the surface concentration of $\mathrm{Fc}$ and the oxidation current both increase again. Additionally, the ion transfer of $\mathrm{Fc}^{+}$has a small contribution to the net current.
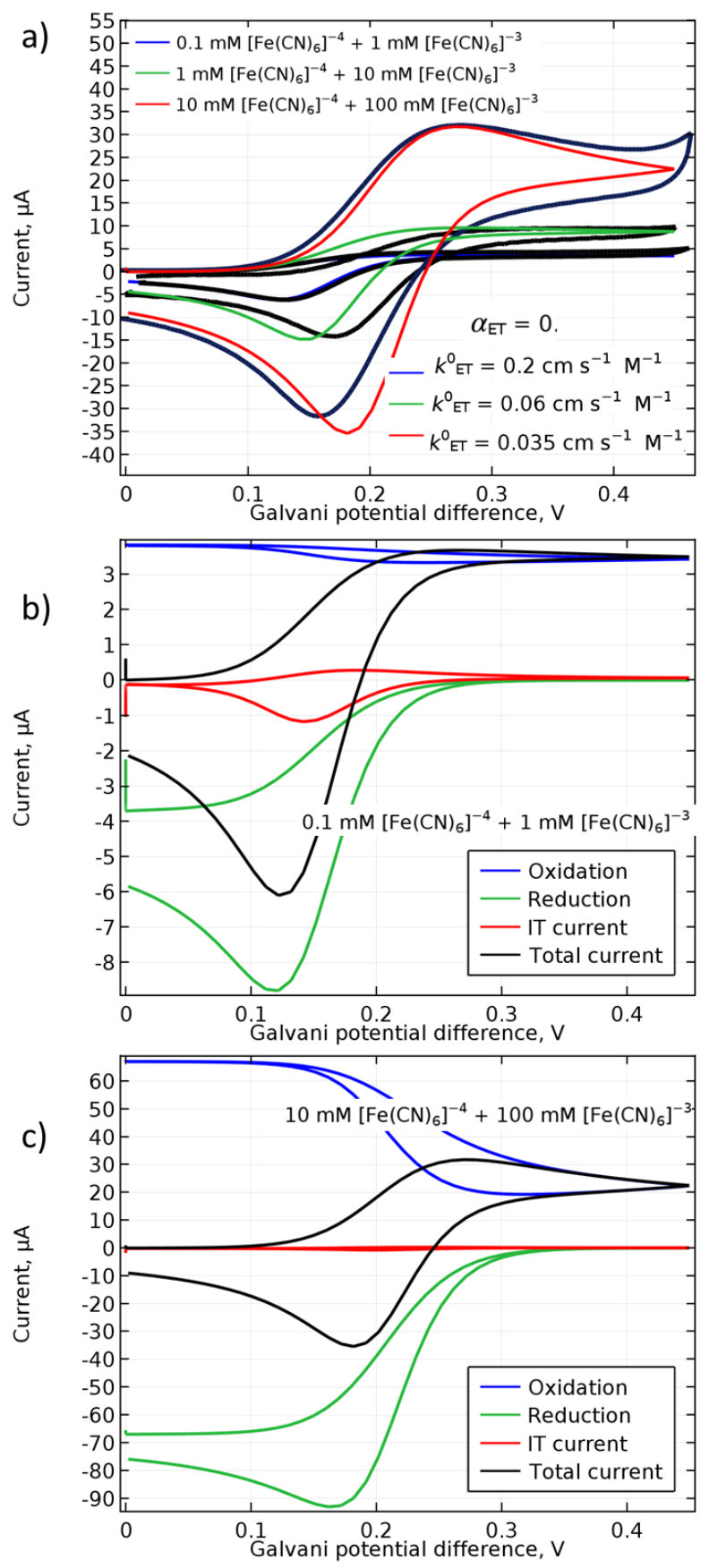

Figure 6. Effect of $\boldsymbol{k E T}_{\mathrm{ET}}$ and contribution of IT and ET currents to the observed current. a) Comparison of the experimental voltammograms obtained with Cells 4-6 and simulated voltammograms obtained by varying the $k^{0}$, with $\alpha$ set as 0 . b) Contribution of the interfacial 
oxidation and reduction of $\mathrm{Fc}$ and ion transfer of $\mathrm{Fc}^{+}$on the total current for low aqueous iron concentration (Cell 6) and c) for high aqueous iron concentration (Cell 4). Scan rate $100 \mathrm{mV} \cdot \mathrm{s}^{-1}$.

\subsubsection{Mixed mechanisms}

A third option to fit the experimental data would be the combination of the interfacial heterogeneous electron transfer and homogeneous electron transfer. In this case, the $\alpha$ value for the interfacial electron transfer was fixed close to 0 , with the standard electron transfer rate constant $\left(k_{0}\right)$ fixed at $0.01 \mathrm{~cm} \cdot \mathrm{s}^{-1} \cdot \mathrm{M}^{-1}$, and the homogeneous rate constant $\left(k_{1}\right)$ was varied to reproduce the experimental voltammograms. In this case $k_{1}$ could be $c a$. halved in comparison with the case considering only homogeneous electron transfer, as shown in Figure 7.The most of the observed current results still from homogeneous reaction followed by ion transfer, but at higher $\mathrm{Fe}^{3+}$ concentrations the electron transfer mechanism starts to also play a more significant role, as shown in Figure 8. However, more accurate simulations considering also the effect of the double layers would be required to clarify this issue.
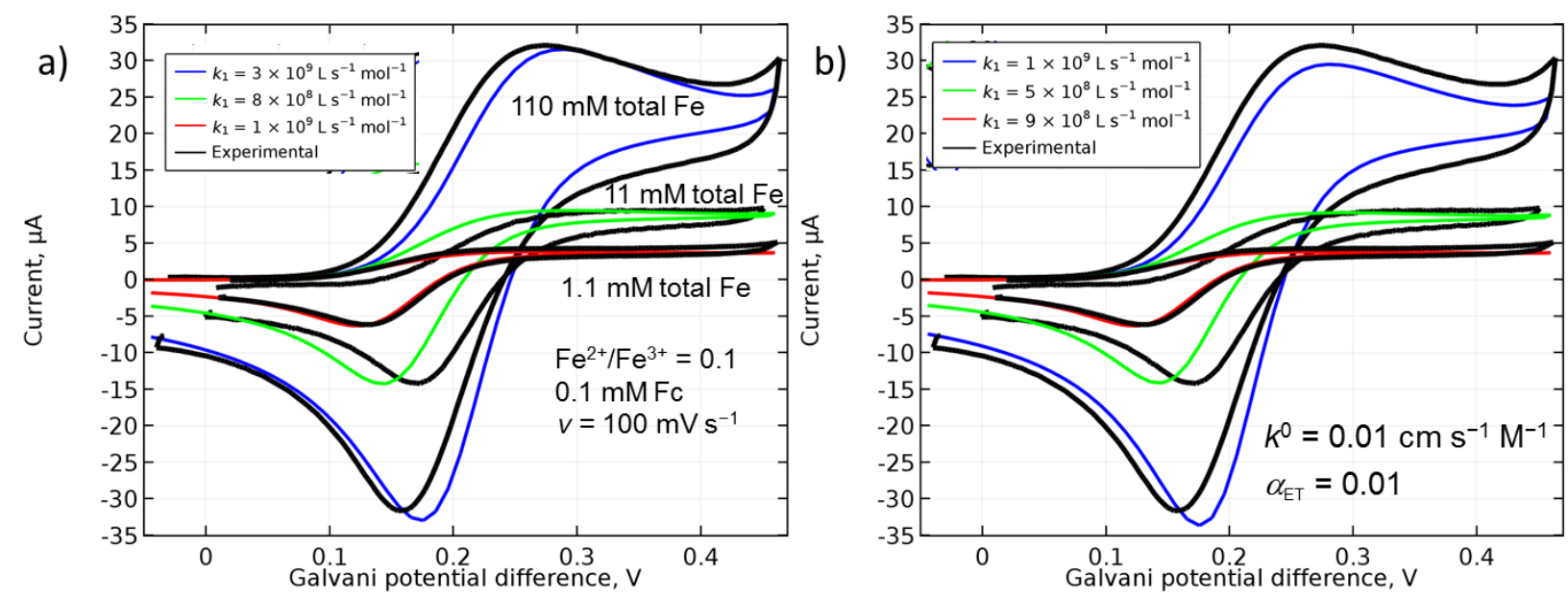

Figure 7. The comparison of the experimental and simulated voltammograms considering only ion transfer mechanism a) or ion transfer mechanism and interfacial electron transfer with very low $\alpha_{\mathrm{ET}}$ value for forward reaction $\left.\mathrm{b}\right)$. Scan rate $100 \mathrm{mV} \cdot \mathrm{s}^{-1}$. 

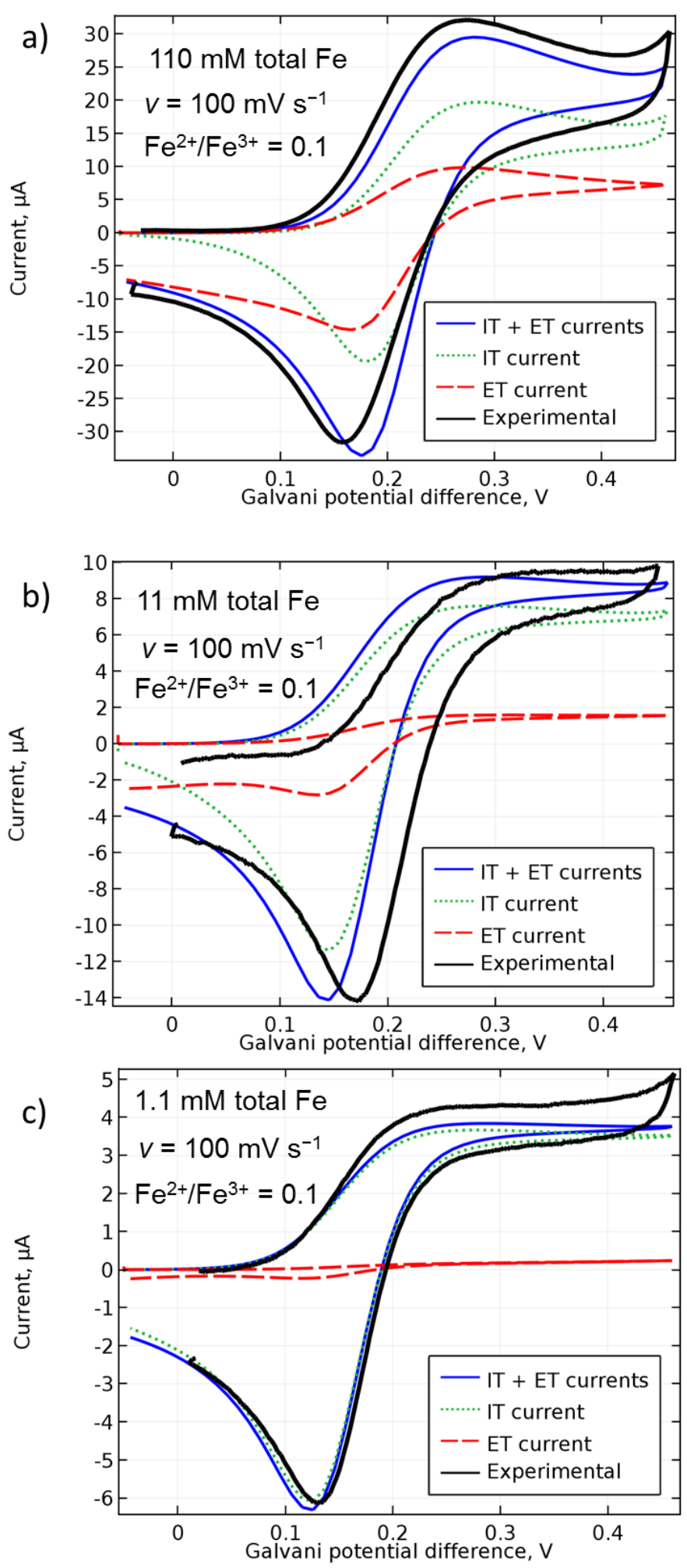
Figure 8. The simulated contributions for the observed current from interfacial electron transfer (ET) and from ion transfer across the interface (IT). The rate constant $k_{1}$ was set as in Figure $8, k^{0}=0.01 \mathrm{~cm} \cdot \mathrm{s}^{-1} \cdot \mathrm{M}^{-1}$ and $\alpha_{\mathrm{ET}}=0.01$.

The mixed mechanism can satisfactorily reproduce the experimental data only if the $\alpha_{\mathrm{ET}}$ is set close to zero. If $\alpha_{\mathrm{ET}}$ would be set to 0.5 , the peak current on the forward sweep would be to high unless $k^{0}$ would be set to very low value. In this case the situation would be as in Fig. 7a, so that the all the reaction would take place by the ion transfer mechanism. To reproduce the experimental data, both ion transfer mechanism and interfacial electron transfer mechanism should show similar behavior, and this is only achieved when $\alpha_{\mathrm{ET}}$ is set to very low value.

\subsubsection{Heterogeneous versus Homogeneous electron transfer reactions at liquid-liquid interfaces: The wrong question?}

In the introduction, we asked several questions concerning the electron transfer reactions observed at liquid-liquid interfaces, and in this section we conclude what we learned from the present experiments and simulations.

i) How much of the total interfacial potential drop does the precursor $\langle D| A>$ "feel" at the interface?

Unfortunately, this question cannot be answered completely based on this work. However, if we assume that the interface is molecularly sharp and the potential drop occurs at the nm range [30], and we assume that all the parameters like electrochemical chemical potentials of species, relative permittivity, density etc. vary smoothly within this thin layer, we can try give some estimations. We also need to consider the size and the orientation of the precursor $\langle\mathrm{D} \mid \mathrm{A}\rangle$. The crystallographic radii of $\mathrm{Fc}$ and $\left[\mathrm{Fe}(\mathrm{CN})_{6}\right]^{3-}$ are $0.33-0.365 \mathrm{~nm}[60,61]$ and $0.475 \mathrm{~nm}$ (computational crystallographic radius, [62]), respectively, so the precursor spans over this extremely thin interface. Another question is then, what is the closest approach for the different species to the interface. To observe the current experimentally, the interface has to be polarized positively. This would push negatively charged ions like $\left[\mathrm{Fe}(\mathrm{CN})_{6}\right]^{3-}$ from the interface further into the aqueous side. On the other hand, Fc can partition into the aqueous phase, although with a 
high partition coefficient of $c a .13400$ favoring the TFT phase. This suggests that the reaction would take place in the aqueous phase, without the precursor "feeling" almost any potential drop. When the charge transfer has taken place, the positively charged $\mathrm{D}^{+}$will move towards the interface while the negatively charged $\mathrm{A}^{-}$will move further away, reducing the probability for the back-reaction. In conclusion, the present data indicates that the precursor does not feel the potential drop.

\section{ii) Where does the potential dependence of the observed current stem?}

Both reaction (2) and (3) can successfully reproduce the experimental data. However, while the homogeneous rate constant increases with increasing ionic strength as shown in Fig. 5, the heterogeneous rate constant $k^{0}$ decreases. As this decrease is difficult to justify theoretically, only reaction (2) does not seem likely. Therefore, there are two possibilities: either the current originates from reaction (3) followed by transfer of $\mathrm{D}^{+}$, or the current is due to the sum of reactions (2) with $\alpha$ close to 0 and (3). As the current-potential response is similar from both reactions (2) and (3), it is difficult to comprehensively answer this question with only cyclic voltammetry, and more sensitive techniques are required to answer these questions.

In case of the heterogeneous electron transfer scenario, if $\alpha=0$, it means that the rate of oxidation of ferrocene does not directly depend on the applied Galvani potential difference, but instead the reaction rate is dependent on the interfacial concentrations. However, the back reduction rate still depends on the applied potential, as shown in Fig. 7 b) and c). The oxidation can only take place when sufficient Galvani potential difference is applied to significantly reduce the rate of the reduction, otherwise both reactions are in equilibrium and the net current flow is zero. In fact, there is a striking similarity with the heterogeneous electron transfer mechanism with $\alpha=0$ and with the homogeneous pre-partitioning mechanism. In both cases, the rate of the ferrocene oxidation does not directly depend on the potential, but is limited by another potential dependent reaction: in the case of the ET mechanism the reaction is the heterogeneous reduction, while in the case of the pre-partitioning mechanism the limiting reaction is the ion transfer of ferrocenium back to the organic phase. If the ferrocenium cannot transfer into the organic phase, the homogeneous reaction reaches equilibrium and does not proceed anymore. Hence, it is not 
surprising that both mechanisms can successfully reproduce the experimental data. This was actually pointed out by Senda et al. [18].

In conclusion, it appears that in the pre-partitioning mechanism the observed potential dependence stems from that of the concomitant ion transfer reactions. This may also explain some earlier observations of the potential independent interfacial electron transfer: if the reactions are studied in the potential range where the concomitant ion transfer reaction is very slow, there will be almost no potential dependence.

Finally, the question about the homogeneous or heterogeneous reaction is perhaps not the most important one. This work shows that a more relevant question is: Can the electron transfer reaction be considered as independent of the applied potential? The answer being most likely: Yes.

\subsubsection{Redox catalysis by a gold nanofilm}

In the presence of a gold film at the interface formed by adsorption of gold nanoparticles, a model treating the gold film as a bipolar metallic thin film electrode with separate Butler-Volmer kinetics for both $\mathrm{Fc}^{+} / \mathrm{Fc}$ and $\mathrm{Fe}^{2+} / \mathrm{Fe}^{3+}$ was also employed. The rate constant of $0.04 \mathrm{~cm} \cdot \mathrm{s}^{-1}$ on gold electrode in accordance with work of Samec et al. [47] was used for the hexacyanoferrate, and the rate constant of ferrocenium/ferrocene reaction $\left(k_{\mathrm{o}}^{0}\right)$ was varied to obtain satisfactory similarity with the experimental voltammograms (Fig. 9), resulting in rate constants of 0.1-0.01 $\mathrm{cm} \cdot \mathrm{s}^{-1}$. 
(A)

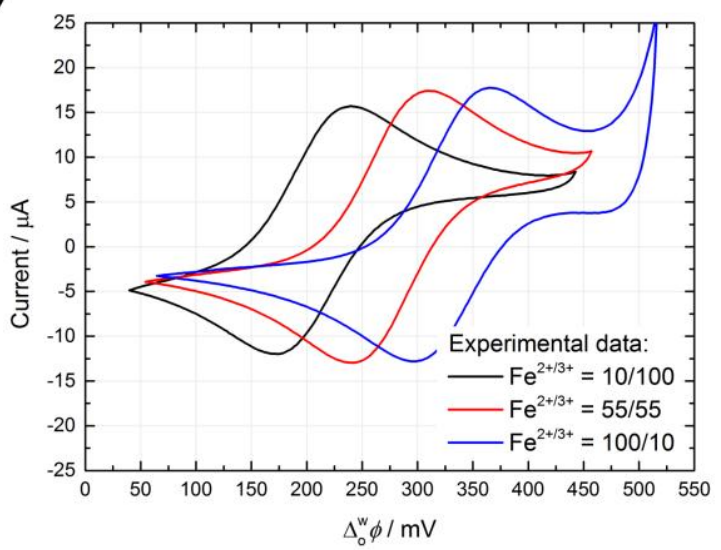

(B)

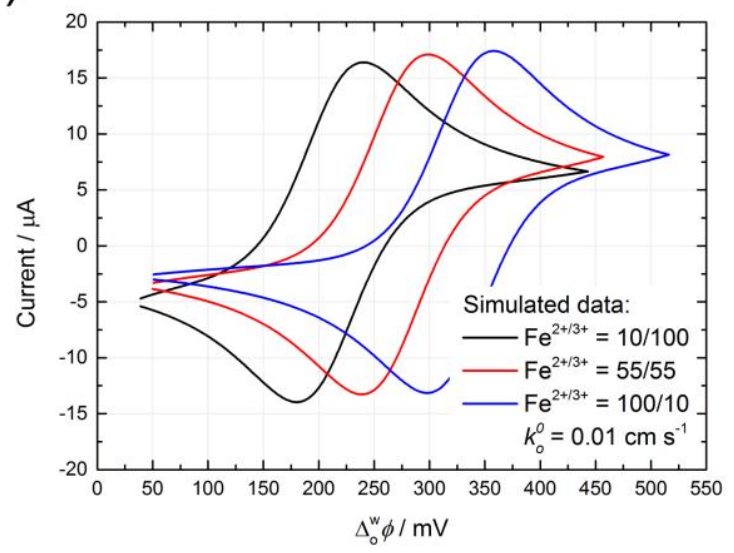

Figure 9. Experimental and simulated cyclic voltammograms (IR compensated) with a gold nanofilm deposited at the interface. $0.1 \mathrm{mM} \mathrm{Fc}$ and $\left[\mathrm{Fe}(\mathrm{CN})_{6}\right]^{3-/ 4}$ with various ratio between $\mathrm{Fe}^{2+}$ and $\mathrm{Fe}^{3+}$ were used. Scan rate $10 \mathrm{mV} \cdot \mathrm{s}^{-1}$. Simulated $\mathrm{CVs}$ were obtained considering a model where AuNP nanofilm act as bipolar electrodes at the interface.

Comparison of experimental and simulated CVs show that the CV obtained with the $\mathrm{Fe}^{2+} / \mathrm{Fe}^{3+}$ has lower current, but otherwise the match is very good. The CVs show that the electron transfer reactions are limited by the mass transport of $\mathrm{Fc} / \mathrm{Fc}^{+}$, so it is difficult to compare different plausible mechanisms. In fact, the model results were almost identical with the simulated voltammetry of ferrocene obtained on a solid electrode. In the simulations, the Galvani potential difference was set between the organic and the aqueous phase, while the potential drop in the metal film in the middle was calculated from Ohms law (and being negligible). So in practice the 
film could be considered equipotential. A bipolar model allows separation of the overpotentials required to drive both reactions. In this case, the amount of $\mathrm{Fe}^{3+}$ in the aqueous phase was so high that practically all the overpotential was on the organic side.

One could also argue that the gold nanofilm catalyzes strongly the heterogeneous interfacial electron transfer between $\mathrm{Fc}$ and $\mathrm{Fe}^{3+}$, but in this case rate constants of 0.1 to $1 \mathrm{~cm} \cdot \mathrm{s}^{-1} \cdot \mathrm{M}^{-1}$ would be required to obtain reversible CVs. Hence, the bipolar electrode model is more likely, and this model is supported by the observation of nanofilm catalyzed interfacial oxygen reduction by DMFc in the organic phase. These numerical simulations collaborate the simplified models for interfacial redox catalysis presented in ref. [35].

Another interesting question is, how the Galvani potential difference is distributed across the interfaces covered with the gold nanofilm.

At the metal-solution interface, a redox equilibrium gives $[63,64]$

$$
F\left(\begin{array}{ll}
\mathrm{M} & \mathrm{S}
\end{array}\right)=\left[\begin{array}{ccc}
0, \mathrm{~S} & 0, \mathrm{~S} \\
\mathrm{ox} & \mathrm{red} & \mathrm{M} \\
e^{-}
\end{array}\right]+R T \ln \left(\frac{a_{\mathrm{ox}}}{a_{\mathrm{red}}}\right)
$$

where ${ }_{e^{-}}^{\mathrm{M}}$ is the chemical contribution to the electrochemical potential of the electron that can be expressed as

$$
\underset{e^{-}}{\mathrm{M}}=\underset{e^{-}}{\mathrm{M}}+F=\stackrel{\mathrm{M}}{e^{-}}+F
$$

where $\frac{\mathrm{M}}{e^{-}}$is the real potential of electrons in metal (the work to bring an electron from vacuum into the metal), is the surface potential of polycrystalline gold in solution and $\begin{gathered}\mathrm{M} \\ e^{-}\end{gathered}$is the work function of gold. By definition, $\quad \begin{gathered}\mathrm{M} \\ e^{-}\end{gathered}=\begin{gathered}\mathrm{M} \\ e^{-}\end{gathered} \quad F \quad$ and $\quad \underset{e^{-}}{\mathrm{M}}=\quad \begin{aligned} & \mathrm{M} \\ & e^{-}\end{aligned}[63,64]$.

Also, the Nernst equation is

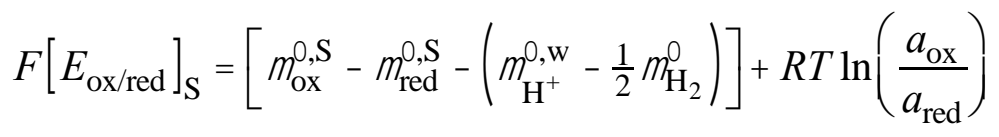

with

$$
\left(\begin{array}{ccc}
0, \mathrm{w} & \frac{1}{2} & 0 \\
\mathrm{H}^{+} & \mathrm{H}_{2}
\end{array}\right) / F=4.44 \mathrm{~V}
$$

Then, the Galvani potential difference is given by 


$$
\mathrm{M} \quad \mathrm{S}=\left[E_{\mathrm{ox} / \mathrm{red}}\right]_{\mathrm{S}}+\left(\begin{array}{ccc}
0, \mathrm{w} & \frac{1}{2} & 0 \\
\mathrm{H}^{+} & H_{2}
\end{array}\right) / F \quad \begin{array}{ll}
\mathrm{M} & e^{-}
\end{array}
$$

So for the $55 \mathrm{mM} / 55 \mathrm{mM}$ ferri-ferro cyanide side, we have

$$
\begin{array}{ll}
\text { M } \quad{ }^{\mathrm{w}}=0.467 \mathrm{~V}+4.44 \mathrm{~V} \quad 5.30 \mathrm{~V}+=0.393 \mathrm{~V}+ \\
\mathrm{M} \quad{ }^{\mathrm{o}}=0.736 \mathrm{~V}+4.44 \mathrm{~V} \quad 5.30 \mathrm{~V}+=0.124 \mathrm{~V}+
\end{array}
$$

as illustrated in Scheme 2 considering that $\chi=0$.

The half-wave Galvani potential difference for the electron transfer reaction then becomes

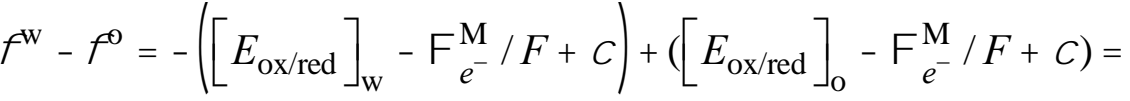

$$
\begin{aligned}
& =\left[E_{\mathrm{ox} / \mathrm{red}}\right]_{\mathrm{o}}\left[E_{\mathrm{ox} / \mathrm{red}}\right]_{\mathrm{W}}=0.269 \mathrm{~V}
\end{aligned}
$$

as can be seen in Figs. 5c-d and 9. This is actually the same expression as can be derived considering the thermodynamic equilibrium of eq. $4[2,3]$. Herein the value of $\left[E_{\mathrm{Fc}^{+} / \mathrm{Fc}}\right]_{\mathrm{O}}$ was tuned from $0.72 \mathrm{~V}$ to $0.736 \mathrm{~V}$ to reproduce the experimental voltammograms in Figure 9.

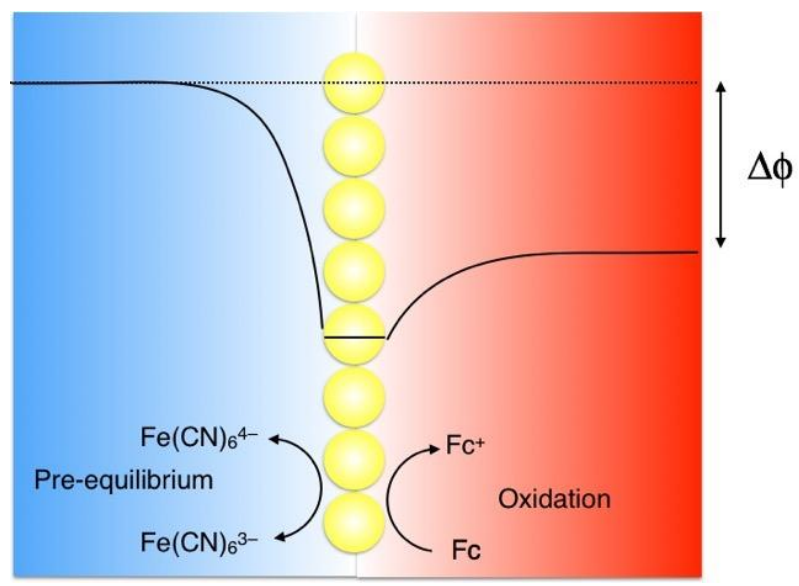

Scheme 2. Potential profile with gold nanofilm covered interface at the half-wave potential of electron transfer reaction with Cell 2, considering that $\chi=0$. The Fermi levels of electrons in all phases are equal at this applied Galvani potential difference.

In any case, the gold nanofilm acts as an array of microelectrode with an overlapping diffusion field thereby preventing the partition of the ferrocene in the aqueous phase. As the gold film is in pre-equilibrium with the aqueous redox couple, this half-wave potential for this mediated ET 
reactions corresponds to Eq. (22). In this pre-equilibrium situation, the Fermi level of the electrons in water and in the gold NPs is equal.

The major difference between Figures 1 and 9 stems from both the reaction kinetics and mass transfer. In Figure 1 the ET reaction in water is kinetically limited whereas the ion transfer reactions are mass transfer controlled. In Figure 9 the mass transfer of the organic redox couple limits the ET reaction at the gold nanofilm.

\section{Conclusions}

The electron transfer between ferrocene dissolved in the organic phase, and ferri/ferrocyanide dissolved in the aqueous phase was studied by cyclic voltammetry and by finite element simulations. These results indicate that electron transfer between slightly partitioning neutral species in the organic phase takes place by the so-called pre-partition mechanism, where ferrocene firstly partitions into the aqueous phase to react homogeneously with $\mathrm{Fe}^{3+}$ species. The observed current results from the transfer of ferrocenium cation back from aqueous to oil phase. The rate constant of the homogeneous electron transfer reaction in the aqueous phase was found to be strongly dependent on the ionic strength of the aqueous phase, varying from $8 \times 10^{8} \mathrm{~s}^{-1} \cdot \mathrm{M}^{-}$ 1 to $1 \times 10^{10} \mathrm{~s}^{-1} \cdot \mathrm{M}^{-1}$, with a linear correlation between $\log k$ and $\sqrt{I} /(1+\sqrt{I})$. Accurate measurements are complicated by the side reactions of ferrocenium, and in some cases by precipitation of Prussian Blue type salts. When a gold nanofilm was added to the liquid-liquid interface, the electron transfer mechanism changed to bipolar mechanism, where the nanofilm acts as a bipolar electrode, shuttling the electrons between the redox couples in different phases and drastically increasing the electron transfer rate.

However, our results cannot completely rule out interfacial electron transfer mechanism where $\alpha$ is close to 0 due to the Frumkin effects, or the mixed mechanism where both interfacial electron transfer mechanism with $\alpha$ close to 0 and the pre-partitioning mechanism operate in tandem. It is not surprising that all the three mechanisms can accurately reproduce the experimental data, as both cases a potential independent step is coupled with a potential dependent reaction (reduction 
of $\mathrm{Fc}^{+}$in the case of interfacial electron transfer mechanism whit $\alpha$ close to 0 , and ion transfer of $\mathrm{Fc}^{+}$in the case of the pre-partitioning mechanism).

To conclude, the question about the homogeneous or heterogeneous reaction is perhaps not the most important one. This work shows that a more relevant question is: Can the electron transfer reaction be considered as independent of the applied potential? The answer being most likely: Yes.

\section{Acknowledgements}

We would like to acknowledge financial support from Swiss National Science Foundation (Grant: Solar Fuels 2000-20_152 557/1), Fondazione Oronzio e Niccolò De Nora, and EPFL.

\section{References}

[1] E.J.W. Verwey, K.F. Niessen, The electrical double layer at the interface of two liquids, Philos. Mag. 28 (1939) 435-446. doi:10.1080/14786443908521199.

[2] H.H. Girault, D.J. Schiffrin, Electrochemistry of liquid-liquid interfaces, in: A.J. Bard (Ed.), Electroanalytical Chemistry: A Series of Advances, Marcel Dekker, New York, 1989: pp. 1-141.

[3] H.H. Girault, Electrochemistry at liquid-liquid interfaces, in: A.J. Bard, C.G. Zoski (Eds.), Electroanalytical Chemistry: A Series of Advances, Taylor \& Francis, Boca Raton, FL, 2010: pp. 1-104.

[4] J. Koryta, Electrochemical polarization phenomena at the interface of two immiscible electrolyte solutions, Electrochim. Acta. 24 (1979) 293-300. doi:10.1016/00134686(79)85048-3.

[5] D. Homolka, L.Q. Hung, A. Hofmanova, M.W. Khalil, J. Koryta, V. Marecek, et al., Faradaic ion transfer across the interface of two immiscible electrolyte solutions: chronopotentiometry and cyclic voltammetry, Anal. Chem. 52 (1980) 1606-1610. doi:10.1021/ac50061a017.

[6] J. Koryta, P. Vanýsek, M. Březina, Electrolysis with an electrolyte dropping electrode, J. Electroanal. Chem. Interfacial Electrochem. 67 (1976) 263-266. doi:10.1016/S00220728(76)80341-5.

[7] Z. Samec, V. Mareček, J. Weber, Charge transfer between two immiscible electrolyte solutions: Part IV. Electron transfer between hexacyanoferrate(III) in water and ferrocene in nitrobenzene investigated by cyclic voltammetry with four-electrode system, J. Electroanal. Chem. Interfacial Electrochem. 103 (1979) 11-18. doi:10.1016/S00220728(79)80475-1. 
[8] Z. Samec, V. Mareček, J. Weber, D. Homolka, Charge transfer between two immiscible electrolyte solutions: Part VII. Convolution potential sweep voltammetry of Cs+ ion transfer and of electron transfer between ferrocene and hexacyanoferrate(III) ion across the water/nitrobenzene interface, J. Electroanal. Chem. Interfacial Electrochem. 126 (1981) 105-119. doi:10.1016/S0022-0728(81)80422-6.

[9] Z. Samec, Charge transfer between two immiscible electrolyte solutions: Part I. Basic equation for the rate of the charge transfer across the interface, J. Electroanal. Chem. Interfacial Electrochem. 99 (1979) 197-205. doi:10.1016/S0022-0728(79)80247-8.

[10] P.D. Beattie, Charge Transfer Across Liquid-Liquid Interfaces - Theory \& Applications, University of Edinburgh, 1995.

[11] Z. Samec, V. Mareček, J. Weber, Detection of an electron transfer across the interface between two immiscible electrolyte solutions by cyclic voltammetry with four-electrode system, J. Electroanal. Chem. Interfacial Electrochem. 96 (1979) 245-247. doi:10.1016/s0022-0728(79)80382-4.

[12] Z. Samec, V. Mareček, J. Weber, Charge transfer between two immiscible electrolyte solutions, J. Electroanal. Chem. Interfacial Electrochem. 100 (1979) 841-852. doi:10.1016/S0022-0728(79)80203-X.

[13] S. Kihara, M. Suzuki, K. Maeda, K. Ogura, M. Matsui, Z. Yoshida, The electron transfer at a liquid / liquid interface studied by current-scan polarography at the electrolyte dropping electrode, J. Electroanal. Chem. Interfacial Electrochem. 271 (1989) 107-125. doi:10.1016/0022-0728(89)80068-3.

[14] H. Hotta, S. Ichikawa, T. Sugihara, T. Osakai, Clarification of the Mechanism of Interfacial Electron-Transfer Reaction between Ferrocene and Hexacyanoferrate(III) by Digital Simulation of Cyclic Voltammograms, J. Phys. Chem. B. 107 (2003) 9717-9725. doi:10.1021/jp035058p.

[15] H. Tatsumi, H. Katano, Cyclic Voltammetry of the Electron Transfer Reaction between Bis(cyclopentadienyl)iron in 1,2-Dichloroethane and Hexacyanoferrate in Water, Anal. Sci. 23 (2007) 589-591. doi:10.2116/analsci.23.589.

[16] H. Tatsumi, H. Katano, Voltammetric study of the interfacial electron transfer between bis(cyclopentadienyl)iron in 1,2-dichloroethane and in nitrobenzene and hexacyanoferrate in water, J. Electroanal. Chem. 592 (2006) 121-125. doi:10.1016/j.jelechem.2006.05.011.

[17] A.A. Stewart, J.A. Campbell, H.H. Girault, M. Edddowes, Cyclic Voltammetry for Electron Transfer Reactions at Liquid/Liquid Interfaces, Berichte Der Bunsengesellschaft Für Phys. Chemie. 94 (1990) 83-87. doi:10.1002/bbpc.19900940117.

[18] H. Tatsumi, H. Katano, M. Senda, Theory of normal-pulse voltammetric current of electron transfer reaction at liquid/liquid interface, J. Electroanal. Chem. 590 (2006) 8289. doi:10.1016/j.jelechem.2006.03.001.

[19] M. Tsionsky, A.J. Bard, M. V. Mirkin, Scanning Electrochemical Microscopy. 34. Potential Dependence of the Electron-Transfer Rate and Film Formation at the Liquid/Liquid Interface, J. Phys. Chem. 100 (1996) 17881-17888. doi:10.1021/jp9612700.

[20] B. Liu, M. V. Mirkin, Potential-Independent Electron Transfer Rate at the Liquid/Liquid 
Interface, J. Am. Chem. Soc. 121 (1999) 8352-8355. doi:10.1021/ja991316d.

[21] C. Shi, F.C. Anson, Simple Electrochemical Procedure for Measuring the Rates of Electron Transfer across Liquid/Liquid Interfaces Formed by Coating Graphite Electrodes with Thin Layers of Nitrobenzene, J. Phys. Chem. B. 102 (1998) 9850-9854. doi: $10.1021 / \mathrm{jp} 982605$.

[22] A.L. Barker, P.R. Unwin, Assessment of a Recent Thin-Layer Method for Measuring the Rates of Electron Transfer across Liquid/Liquid Interfaces, J. Phys. Chem. B. 104 (2000) 2330-2340. doi:10.1021/jp993373z.

[23] K. Aoki, Size-distribution of droplets in emulsions by statistical mechanics calculation, J. Colloid Interface Sci. 360 (2011) 256-261. doi:10.1016/j.jcis.2011.04.054.

[24] M. Li, K. Aoki, J. Chen, T. Nishiumi, Voltammetric determination of concentrations of ferrocene-included nitrobenzene droplets in water, J. Electroanal. Chem. 655 (2011) 159163. doi:10.1016/j.jelechem.2011.02.015.

[25] K. Aoki, M. Li, J. Chen, T. Nishiumi, Spontaneous emulsification at oil-water interface by tetraalkylammonium chloride, Electrochem. Commun. 11 (2009) 239-241. doi:10.1016/j.elecom.2008.11.012.

[26] M. Zhou, S. Gan, L. Zhong, X. Dong, L. Niu, Which mechanism operates in the electrontransfer process at liquid/liquid interfaces?, Phys. Chem. Chem. Phys. 13 (2011) 2774-9. doi:10.1039/c0cp01692f.

[27] W. Schmickler, Electron-transfer reactions across liquid|liquid interfaces, J. Electroanal. Chem. 428 (1997) 123-127. doi:10.1016/S0022-0728(96)05076-0.

[28] Z. Samec, Dynamic electrochemistry at the interface between two immiscible electrolytes, Electrochim. Acta. 84 (2012) 21-28. doi:10.1016/j.electacta.2012.03.118.

[29] Z. Ding, D.J. Fermín, P.-F. Brevet, H.H. Girault, Spectroelectrochemical approaches to heterogeneous electron transfer reactions at the polarised water|1,2-dichloroethane interfaces, J. Electroanal. Chem. 458 (1998) 139-148. doi:10.1016/S00220728(98)00341-6.

[30] B. Hou, N. Laanait, H. Yu, W. Bu, J. Yoon, B. Lin, et al., Ion distributions at the water/1,2-dichloroethane interface: potential of mean force approach to analyzing X-ray reflectivity and interfacial tension measurements., J. Phys. Chem. B. 117 (2013) 5365-78. doi:10.1021/jp401892y.

[31] H. Yu, I. Yzeiri, B. Hou, C.-H. Chen, W. Bu, P. Vanysek, et al., Electric Field Effect on Phospholipid Monolayers at an Aqueous-Organic Liquid-Liquid Interface., J. Phys. Chem. B. (2014). doi:10.1021/jp5098525.

[32] J.K. Cooper, I. Benjamin, Photoinduced Excited State Electron Transfer at Liquid/Liquid Interfaces, J. Phys. Chem. B. 118 (2014) 7703-7714. doi:10.1021/jp409541u.

[33] E.A. McArthur, K.B. Eisenthal, Ultrafast excited-state electron transfer at an organic liquid/aqueous interface., J. Am. Chem. Soc. 128 (2006) 1068-9. doi:10.1021/ja056518q.

[34] D. Ibañez, D. Plana, A. Heras, D.J. Fermín, A. Colina, Monitoring charge transfer at polarisable liquid/liquid interfaces employing time-resolved Raman spectroelectrochemistry, Electrochem. Commun. $54 \quad$ (2015) 14-17. 
doi:10.1016/j.elecom.2015.02.012.

[35] E. Smirnov, P. Peljo, M.D. Scanlon, H.H. Girault, Interfacial Redox Catalysis on Gold Nanofilms at Soft Interfaces, ACS Nano. 9 (2015) 6565-6575. doi:10.1021/acsnano.5b02547.

[36] I. Hatay, B. Su, F. Li, M.A. Méndez, T. Khoury, C.P. Gros, et al., Proton-coupled oxygen reduction at liquid-liquid interfaces catalyzed by cobalt porphine., J. Am. Chem. Soc. 131 (2009) 13453-9. doi:10.1021/ja904569p.

[37] H. Deng, T.J. Stockmann, P. Peljo, M. Opallo, H.H. Girault, Electrochemical oxygen reduction at soft interfaces catalyzed by the transfer of hydrated lithium cations, J. $\begin{array}{lllll}\text { Electroanal. } & \text { Chem. } & 731 & \text { 28-35. }\end{array}$ doi:http://dx.doi.org/10.1016/j.jelechem.2014.07.040.

[38] H. Deng, P. Peljo, T.J. Stockmann, L. Qiao, T. Vainikka, K. Kontturi, et al., Surprising acidity of hydrated lithium cations in organic solvents, Chem. Commun. (Cambridge, United Kingdom). 50 (2014) 5554-5557. doi:10.1039/C4CC01892C.

[39] S. Wilke, T. Zerihun, Standard Gibbs energies of ion transfer across the water|2nitrophenyl octyl ether interface, J. Electroanal. Chem. 515 (2001) 52-60. doi:10.1016/S0022-0728(01)00640-4.

[40] A.J. Olaya, P. Ge, H.H. Girault, Ion transfer across the water|trifluorotoluene interface, Electrochem. Commun. 19 (2012) 101-104. doi:10.1016/j.elecom.2012.03.010.

[41] ElectroChemical DataBase: Gibbs Energies of transfer, (2016). http://sbsrv7.epfl.ch/instituts/isic/lepa/cgi/DB/InterrDB.pl.

[42] E. Smirnov, P. Peljo, M.D. Scanlon, H.H. Girault, Gold Nanofilm Redox Catalysis for Oxygen Reduction at Soft Interfaces, Electrochim. Acta. (2015). doi:10.1016/j.electacta.2015.10.104.

[43] K.J. Aoki, J. Yu, J. Chen, T. Nishiumi, Participation in Self-Emulsification by Oil-Thin Film Voltammetry, Int. J. Chem. 6 (2014) 73. doi:10.5539/ijc.v6n2p73.

[44] S. Daniele, M.A. Baldo, C. Bragato, A steady-state voltammetric investigation on the oxidation of ferrocene in ethanol-water mixtures, Electrochem. Commun. 1 (1999) 37-41. doi:10.1016/S1388-2481(98)00011-3.

[45] D.J. Fermin, R. Lahtinen, Dynamic Aspects of Heterogeneous Electron-Transfer Reactions at Liquid|Liquid Interfaces, in: A.G. Volkov (Ed.), Liquid Interfaces in Chemical, Biological, and Pharmaceutical Applications, Marcel Dekker Inc., New York, 2001: pp. 179-227.

[46] D. Plana, F.G.E. Jones, R.A.W. Dryfe, The voltammetric response of bipolar cells: Reversible electron transfer, J. Electroanal. Chem. 646 (2010) 107-113. doi:10.1016/j.jelechem.2010.03.020.

[47] V. Mareček, Z. Samec, J. Weber, The dependence of the electrochemical charge-transfer coefficient on the electrode potential, J. Electroanal. Chem. Interfacial Electrochem. 94 (1978) 169-185. doi:10.1016/S0022-0728(78)80312-X.

[48] S.A. Campbell, L.M. Peter, The effect of $[\mathrm{K}+]$ on the heterogeneous rate constant for the $[\mathrm{Fe}(\mathrm{CN}) 6] 3-/[\mathrm{Fe}(\mathrm{CN}) 6] 4-$ redox couple investigated by a.c. impedance spectroscope, J. 
Electroanal. Chem. 364 (1994) 257-260. doi:10.1016/0022-0728(93)02922-5.

[49] A. Singh, D.R. Chowdhury, A. Paul, A kinetic study of ferrocenium cation decomposition utilizing an integrated electrochemical methodology composed of cyclic voltammetry and amperometry., Analyst. 139 (2014) 5747-54. doi:10.1039/c4an01325e.

[50] J.P. Hurvois, C. Moinet, Reactivity of ferrocenium cations with molecular oxygen in polar organic solvents: Decomposition, redox reactions and stabilization, J. Organomet. Chem. 690 (2005) 1829-1839. doi:10.1016/j.jorganchem.2005.02.009.

[51] G. Zotti, G. Schiavon, S. Zecchin, D. Favretto, Dioxygen-decomposition of ferrocenium molecules in acetonitrile: The nature of the electrode-fouling films during ferrocene electrochemistry, J. Electroanal. Chem. 456 (1998) 217-221. doi:10.1016/S00220728(98)00279-4.

[52] B. Quinn, K. Kontturi, Aspects of electron transfer at ITIES, J. Electroanal. Chem. 483 (2000) 124-134. doi:10.1016/S0022-0728(00)00030-9.

[53] B. Quinn, R. Lahtinen, L. Murtomäki, K. Kontturi, Electron transfer at micro liquid-liquid interfaces, Electrochim. Acta. 44 (1998) 47-57. doi:10.1016/S0013-4686(98)00151-0.

[54] C.A. Bunton, G. Cerichelli, Micellar effects upon electron transfer from ferrocenes, Int. J. Chem. Kinet. 12 (1980) 519-533. doi:10.1002/kin.550120803.

[55] A. Zahl, R. van Eldik, T.W. Swaddle, Cation-Independent Electron Transfer between Ferricyanide and Ferrocyanide Ions in Aqueous Solution, Inorg. Chem. 41 (2002) 757764. doi:10.1021/ic010957i.

[56] M.R. Kershaw, J.E. Prue, Specific cation effects on rate of reaction between persulphate and ferrocyanide ions, Trans. Faraday Soc. 63 (1967) 1198-1207. doi:10.1039/TF9676301198.

[57] J. Strutwolf, A.L. Barker, M. Gonsalves, D.J. Caruana, P.R. Unwin, D.E. Williams, et al., Probing liquid|liquid interfaces using neutron reflection measurements and scanning electrochemical microscopy, J. Electroanal. Chem. 483 (2000) 163-173. doi:10.1016/s0022-0728(00)00027-9.

[58] R.A. Marcus, Theory of electron-transfer rates across liquid-liquid interfaces, J. Phys. Chem. 94 (1990) 4152-4155. doi:10.1021/j100373a051.

[59] S. Xie, X. Meng, Z. Liang, B. Li, Z. Chen, Z. Zhu, et al., Kinetics of Heterogeneous Electron Transfer Reactions at the Externally Polarized Water/ o- Nitrophenyl Octyl Ether Interface, J. Phys. Chem. C. 112 (2008) 18117-18124. doi:10.1021/jp802435m.

[60] D.W. Fischer, Crystallographic data for some ferrocene derivatives, Acta Crystallogr. 17 (1964) 619. doi:10.1107/S0365110X64001475.

[61] N.G. Tsierkezos, U. Ritter, Electrochemical impedance spectroscopy and cyclic voltammetry of ferrocene in acetonitrile/acetone system, J. Appl. Electrochem. 40 (2010) 409-417. doi:10.1007/s10800-009-0011-3.

[62] D.J. Carter, M.I. Ogden, A.L. Rohl, Incorporation of cyano transition metal complexes in $\mathrm{KCl}$ crystals - Experimental and computational studies, Aust. J. Chem. 56 (2003) 675678. doi:10.1071/CH02260.

[63] H.H. Girault, Analytical and Physical Electrochemistry, EPFL Press, Lausanne, 2004. 
[64] M.D. Scanlon, P. Peljo, M.A. Méndez, E. Smirnov, H.H. Girault, M.A. Mendez, et al., Charging and discharging at the nanoscale: Fermi level equilibration of metallic nanoparticles, Chem. Sci. 6 (2015) DOI: 10.1039/C5SC00461F. doi:10.1039/C5SC00461F. 